\title{
On the Importance of Secondary Component Properties for Cold Spray Metallization of Carbon Fiber Reinforced Polymers
}

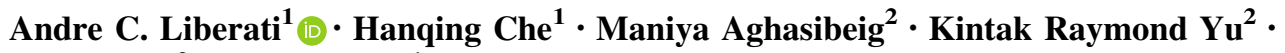 \\ Phuong $\mathrm{Vo}^{2} \cdot$ Stephen Yue ${ }^{1}$
}

Submitted: 15 August 2021 / in revised form: 17 December 2021/Accepted: 21 December 2021/Published online: 2 February 2022 (C) ASM International 2022

\begin{abstract}
In previous studies at McGill University, tin was successfully cold sprayed onto carbon fiber reinforced polymers (CFRPs). A "crack-filling" mechanism was described as the deposition mechanism that allowed deposition of tin onto the CFRP. Improving the coating conductivity for lightning strike protection (LSP) purposes was explored by adding other metal powders (aluminum, copper, zinc) to tin and cold spraying on the CFRP. At the same time, it was noticed that the addition of this secondary component (SC) provided an increase in deposition efficiency (DE); tamping was initially hypothesized to explain this improvement, thus prompting a study solely on the effect of SC hardness. However, it is recognized that other powder characteristics may also be influencing the DE. Thus, in this study, SCs with a wider variety of particle sizes, morphologies, densities and hardness values were mixed with tin and sprayed on CFRPs. The effect of SC properties on tin deposition is discussed and, while SC particle size, morphology and density individually do not notably influence the DE, the impact energy of the SC does. This opens a discussion on optimal parameters for deposition of metals on CFRP, based on results and observations from the literature.
\end{abstract}

This article is an invited paper selected from presentations at the 2021 International Thermal Spray Conference, ITSC2021, that was held virtually May 25-28, 2021 due to travel restrictions related to the coronavirus (COVID-19) pandemic. It has been expanded from the original presentation.

Andre C. Liberati

andre.liberati@mail.mcgill.ca

1 McGill University, Montreal, Canada

2 National Research Council Canada, Boucherville, Canada
Keywords cold spray $<$ processing $\cdot$ carbon fiber reinforced polymers - metallization of polymers $\cdot$ mixed metal powders $\cdot$ powder properties $\cdot$ powder hardness

\section{Introduction}

"Metallizing" or applying metallic coatings onto polymeric substrates has received increasing interest in recent decades (Ref 1), being used extensively for applications from food packaging (Ref 2) to generating heating elements for potential de-icing applications (Ref 3). In recent years, interest has been given to polymers and polymeric composites for structural applications as they possess high strength-to-weight ratios, but low electrical conductivity has limited their use in some fields such as the aerospace industry (Ref 1,4). As a result, different technologies for polymer metallization have been studied. Vacuum deposition techniques, such as physical vapor deposition (PVD) (Ref 5) or chemical vapor deposition (CVD) (Ref 6) have provided potential pathways to metallization of polymers but they are not suitable to fabricate thick metal coatings (over $100 \mu \mathrm{m})($ Ref 7). Other techniques have been considered such as layup molding (Ref 8), wire-arc spray (Ref 9-12), flame spray (Ref 13), plasma spray (Ref 14) or air plasma spray (Ref 15, 16), but cold spray has appeared as one of the most viable approaches as it uses relatively low temperatures (several hundred degrees versus several thousand degrees for other thermal spray techniques), thus limiting the risk of oxidation of the metallic powder and heat damage to the substrate (Ref 17).

Cold spraying metal feedstock onto a metallic substrate is generally efficient, while cold spraying metal powders onto polymeric substrates has provided mixed results as a consequence of substrate erosion from the impact of hard 
particles on a substrate with poor erosion resistance (Ref 18-21). In recent years, metallization of polymers has garnered increased interest (Ref 22, 23) and some success has been obtained in depositing metallic layers on polymeric substrates with a variety of metals, e.g. tin (Ref 18, 24-26), iron ( $\operatorname{Ref} 24), 316 \mathrm{~L}$ stainless steel (Ref 27, 28), AlSi10Mg (Ref 28-30), copper (Ref 18, 24, 26, 31-34) or aluminum (Ref 33, 35). Notably, high deposition efficiencies of over $70 \%$ for copper on PEEK deposition were recently recorded (Ref 32,34$)$. On the other hand, generally reported issues include substrate damage (Ref 18, 26), low deposition efficiencies (DEs) (i.e. the ratio of the weight of the effectively deposited particles to sprayed particles onto the substrate) (Ref 24, 26-29), or delamination (Ref 17, 31-33).

Lupoi and O'Neill (Ref 26) explored the deposition of various metals on polymeric substrates and established an impact energy criterion that would regulate deposition versus erosion of the substrate by the metallic powder. Affi et al. (Ref 17) sprayed micron-sized aluminum directly onto a CFRP substrate, to respect this energetic criterion, but faced debonding of the cold sprayed coating. Shortly afterwards, Ganesan et al. (Ref 19) suggested that soft powders such as tin had the possibility to deform upon impact favoring mechanical anchoring, while harder particles such as copper could not. Che et al. (Ref 18) introduced a "crack filling", mechanism, where it was hypothesized that thermally softened or partially melted tin particles impacted the epoxy-CFRP substrate and, while the harder core of the particle would generate microcracks in the CFRP substrate, the softer outer core would immediately fill the cracks and provide mechanical interlocking with the substrate. Considering the overall deposition process, Che et al. (Ref 24) also advanced the importance of differentiating the process into two separate steps: the first-layer deposition phase (occurring between the metal powder and the substrate) and the build-up phase (occurring between the metal powder and previously deposited metal powders). In other studies discussing thermoplastic (PEEK) substrate metallization, a notable level of substrate deformation was observed, and the deposition mechanism was associated with embedding of copper or aluminum particles into the substrate (Ref 24, 34-36).

In parallel, several researchers proved that mixing ceramic powders in metal feedstock powder may enhance the deposition process, by producing a shot peening effect on the relatively softer feedstock powder (Ref 37-39). This effect has been used to establish an in-situ shot peening cold spray deposition process, that improves deposition and coating properties through the addition of large stainless steel particles (200-300 $\mu \mathrm{m})$ (Ref 40-42). Recently, Fernandez and Jodoin (Ref 43, 44) advanced potential mechanisms explaining the coating deposition improvement (surface roughening by the secondary component (SC) through generation of asperities and oxide removal), as well as the coating property improvement (generation of oxide clean surfaces and peening by the SC). Che et al. (Ref 45) made similar observations related to coating deposition improvement when mixing metallic powders (zinc or copper) with tin powders, and this improvement was associated with the shot-peening effect of the SC on the relatively softer tin.

Nevertheless, in a more recent study (Ref 46), evidence appeared that other factors than shot-peening may play a role. When comparing the DE of pure tin to tin powders mixed with aluminum or aluminum alloy powders on a steel substrate (ideal deposition scenario of a soft metal on a relatively harder metal), no notable improvements were brought by the use of the aluminum/aluminum alloy SCs (Ref 46). Height profiles of the coatings were acquired, and the addition of the SC did not noticeably modify the roughness of the surface. This would imply that surface roughening may not apply during the build-up phase, and so the observed improvement of the DE of tin on the CFRP would not occur in the build-up phase, but necessarily during the first-layer deposition phase (Ref 46). The study suggested that an ideal SC hardness was one of the main causes for deposition improvement, and that this improvement would be most noticeable when the SC hardness was close to the hardness of the substrate: from the perspective of the "crack-filling" mechanism, the nature of the improvement would then originate from the potential of the SC to generate cracks that the impinging tin could fill (Ref 46), and so the quicker the substrate surface would be activated, the quicker the build-up phase could begin.

However, comparisons between powders can be quite difficult as powders possess a variety of properties ranging from the material (density and hardness) to the characteristics of the powder itself (morphology and particle size distribution). Should the improvement be associated to crack generation by the SC at the substrate surface, a certain amount of kinetic energy would need to be transferred to the surface for this to occur. Properties related to particle energy would be associated to particle mass (i.e. density, size) and velocity (morphology, size), while the transfer of this energy would depend on the hardness (i.e. resistance to plastic deformation) of the powder. Furthermore, retention of the SC also seems to be quite correlated with the morphology of the particles (Ref 19, 45). Therefore, in tandem with the results offered by the previous study (Ref 46), this study aims to assess the relative effects of the SC properties and how they lead to the improvement of the DE of tin on CFRP substrates.

In this study, tin mixed with a variety of SC are cold sprayed on CFRP and mild steel substrates to study the 
effect of SC properties on the deposition of pure tin. The choice of SC was based on a factorial-design-like approach, to cover an array of SC properties (hardness, density, morphology, median particle size): the choice of these SCs is described in further detail in the Experimental Methods section. The coatings are sprayed on a variety of different substrates to investigate how different CFRP materials and surface conditions may influence deposition. Tin and tin-SC mixed powders with 90:10 weight ratio are cold sprayed with a low-pressure cold spray system, onto thermosetting epoxy-CFRP substrates with varying surface finishes, a thermoplastic Polyether-Ether-Ketone (PEEK)CFRP and mild steel substrates. Microanalysis and microhardness measurements of the coatings are then performed, and the velocity of the particles is estimated via a CFD model. Finally, the DE is measured to evaluate the effect of the SC properties on the deposition process.

\section{Experimental Methods}

\section{Feedstock Materials}

The feedstock materials used in this work cover a variety of material and powder properties. The SCs were generally chosen as a pure metal with a corresponding alloy to have a variation of hardness with a similar density to the main component, similarly to the choice of $\mathrm{Al}$ and $\mathrm{Al}$ alloys in the previous study (Ref 46). Given previous observations around SC addition to cold spraying of tin onto CFRP substrates (Ref 45,47 ), relations to particle density, hardness and morphology were considered most important to control, while particle size was a variable to be followed. As each commercial powder had a specific combination of these four properties, it was quite difficult to select a powder with a given property without varying the others, and hence, a factorial-design-like approach was employed. In this type of design, several variables of a process are chosen and scaled using the Taylor expansion approximation (Ref 48). The scaling sets the low-value of a variable to -1 and the high-value to +1 . This facilitates a comparison of the variable effects, especially across different ranges. Morphology is relatively difficult to quantify, so it was treated as a discrete variable with the low-level being "Spherical" while the high-level was "Irregular" (i.e. angular, dendritic, or any other non-spherical morphology).

A variety of cold sprayed powders from past studies at McGill University (Ref 45, 49-51) was considered to offer a meaningful spread for each property. As such, copper powders from studies by Che et al. (Ref 18, 45), iron and stainless steel $316 \mathrm{~L}$ powders from studies by Chu et al. (Ref 49, 50) and titanium/Ti6Al4V powders from studies by Wong et al. (Ref 51) were selected. Aluminium/ aluminium alloy powders from previous work (Ref 46) and the results provided by these $\mathrm{SC}$ were considered for comparison, but these SC were not sprayed in mixtures with $\mathrm{Sn}$ in this work. The ranges of considered properties were thus between 2.66 and $8.96 \mathrm{~g} . \mathrm{cm}^{-3}$ for density, 7 and $340 \mathrm{HV}_{0.01}$ for hardness, and 12 and $37 \mu \mathrm{m}$ for median particle size $\left(\mathrm{D}_{50}\right)$. Average impact energy was determined to be between $1.32 \times 10^{-6}$ and $7.30 \times 10^{-6} \mathrm{~J}$. The characterization of the powder hardness, particle size and average impact energy is described in the following sections. The scaled properties of the SC powders considered in this study are listed in Fig. 1. The Al/Al alloy powders offer relatively low values for all properties (lower left quadrant), whereas the copper powders allow the study of higher density, size and morphology values. The Ti/ Ti6Al4V powders give higher hardness values, density below the middle-level, and offer a variety of sizes/morphologies. Finally, the iron/stainless steel $316 \mathrm{~L}$ powders complete the variable spread with intermediate hardness values, density above the middle level, and a variety of sizes/morphologies. As such, the choice of powders should offer a reasonable representation of the SC properties versus the deposition of tin onto CFRP substrates.

Powder mixtures with $90 \mathrm{wt} \%$ tin and $10 \mathrm{wt} \%$ of the $\mathrm{SC}$ were prepared by mixing for $1 \mathrm{~h}$ in a metal can without additional media (e.g., milling balls) using a double movement powder mixer. No significant morphological changes or hardening was noticed in the mixed powder when compared with the starting powders. The absence of morphological changes was verified through scanning electron microscope (SEM) of the mixed powders. Note should be taken that for each SC, the $10 \mathrm{wt} \%$ weight fraction could represent a different volume fraction (based on density) or a different fraction of particles present in the mixture (based on molar mass). For instance, $10 \mathrm{wt} \%$ of $\mathrm{Al}$ in $\mathrm{Sn}$ represents 33 mol.\% or 23 vol.\% of $\mathrm{Al}$, while 10 wt.\%. of $\mathrm{Cu}$ in $\mathrm{Sn}$ represents $17 \mathrm{~mol} . \%$ or 8 vol.\% of $\mathrm{Cu}$, meaning that there are twice as many or thrice the volume of $\mathrm{Al}$ particles participating in the impinging of the substrate and the coating, as compared to $\mathrm{Cu}$ particles (Ref 52). Although not studied here, these metrics could have an impact on the crack-generation on the CFRP or on the deposition of tin.

\section{Powder Characterization}

The various properties for each powder are listed in Table 1. The particle sizes of the feedstock powders were measured with a wet laser diffraction particle size analyzer (FlowSync, Microtrac, PA, USA). The tin powder had a spheroidal morphology and a relatively lower median particle size of $13 \mu \mathrm{m}$ compared to the other powders, which had a median particle size between 20 and $37 \mu \mathrm{m}$. 


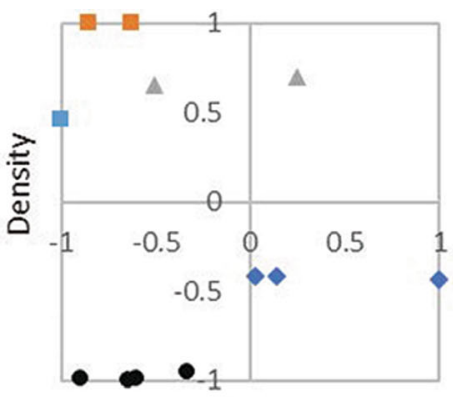

Hardness

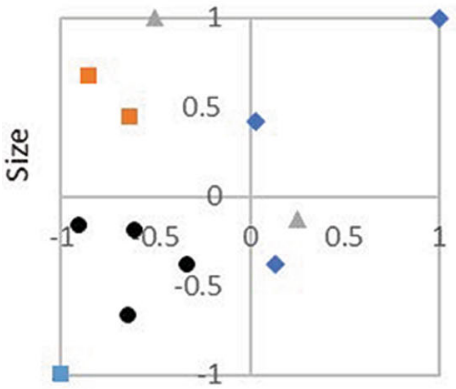

Hardness

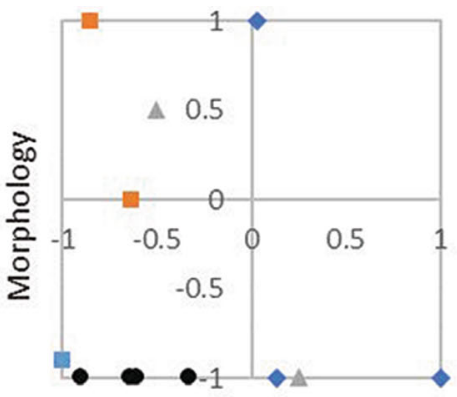

Hardness

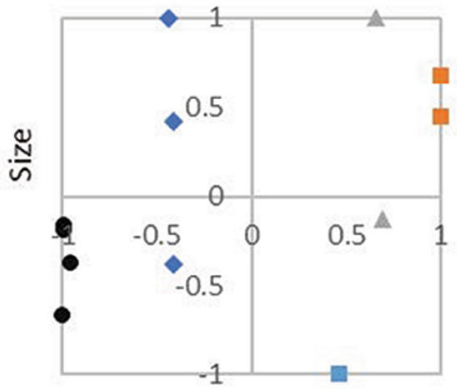

Density

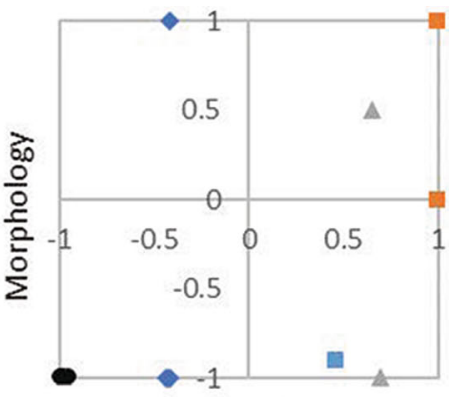

Density

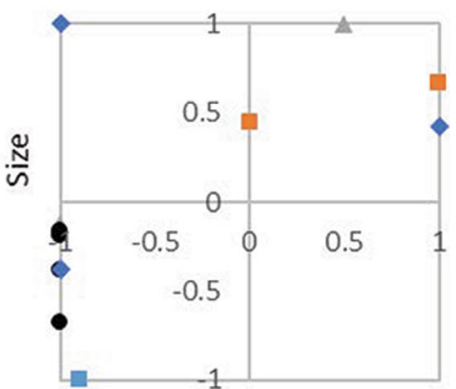

Morphology

$\because \mathrm{Sn} \bullet \mathrm{Al} / \mathrm{Al}$ alloys $[46] \quad \triangle \mathrm{Fe} / \mathrm{SS} 316 \mathrm{~L}[49,50] \quad \mathrm{Cu}[18,45] \bullet \mathrm{Ti} / \mathrm{Ti} 6 \mathrm{Al} 4 \mathrm{~V}[51]$

Fig. 1 Comparison of scaled SC properties. The spread of data points shows the complimentary of the various SC in this study

Table 1 Properties of the feedstock powders used in this work and in previous work (Ref 46)

\begin{tabular}{lllccc}
\hline Powder & Morphology & \multicolumn{1}{c}{ Supplier } & $\mathrm{D}_{50}(\mu \mathrm{m})$ & Hardness $\left(\mathrm{HV}_{0.01}\right)$ & Density $\left(\mathrm{g} \mathrm{cm}^{-3}\right)$ \\
\hline $\mathrm{Sn}$ & Spheroidal & CenterLine & 13 & $8 \pm 1$ & 7.29 \\
$\mathrm{Cu}$ & Mixed & Giken & 30 & $68 \pm 7$ & 8.96 \\
$\mathrm{Cu}-\mathrm{IR}$ & Dendritic & CenterLine & 33 & $32 \pm 4$ & 8.96 \\
$\mathrm{Fe}$ & Mixed/IR & Goodfellow & 37 & $89 \pm 14$ & 7.87 \\
SS316L & Spherical & Sandvik & 23 & $215 \pm 26$ & 8.00 \\
Ti-SP & Spherical & Raymor (AP\&C) & 20 & $196 \pm 22$ & 4.50 \\
Ti-AG & Angular & Cerac & 30 & $178 \pm 34$ & 4.50 \\
Ti6A14V & Spherical & Raymor (AP\&C) & 37 & $340 \pm 14$ & 4.43 \\
Sn (Ref 46) & Spheroidal & CenterLine & 12 & $7 \pm 1$ & 7.29 \\
Al (Ref 46) & Spherical & Valimet & 23 & $24 \pm 2$ & 2.70 \\
A15083 (Ref 46) & Spherical & Valimet & 17 & $66 \pm 11$ & 2.66 \\
Al6061 (Ref 46) & Spherical & Valimet & 23 & $72 \pm 8$ & 2.70 \\
Al7075 (Ref 46) & Spherical & Valimet & 20 & $118 \pm 23$ & 2.81 \\
\hline
\end{tabular}

The SEM images of the single-component powders are presented in Fig. 2. In Fig. 2(a), a broad distribution of particle sizes can be observed for tin, whereas the other powders (Fig. 2b-h) seem to have more homogeneous distributions. This is confirmed by the particle size distributions of the various powders, presented in Fig. 3, where tin presents a broad, almost bi-modal size distribution compared to fairly mono-modal distributions of the other powders. The two copper powders had different morphologies with a mixed spherical/irregular powder $(\mathrm{Cu}$,
Fig. 2b) being complemented by an irregular copper powder (Cu-IR, Fig. 2c). The iron had a mixed morphology, with mostly irregular particles (Fig. 2d), while the stainless steel 316L powder was spherical (Fig. 2e). Finally, titanium powders in the form of both a spherical (Ti-SP, Fig. 2f) and an irregular, angular powder (Ti-AG, Fig. 2g) were complemented by a spherical Ti6Al4V powder (Fig. 2h)

The average Vickers hardness of the feedstock powders was measured by mounting the powders, grinding to a 


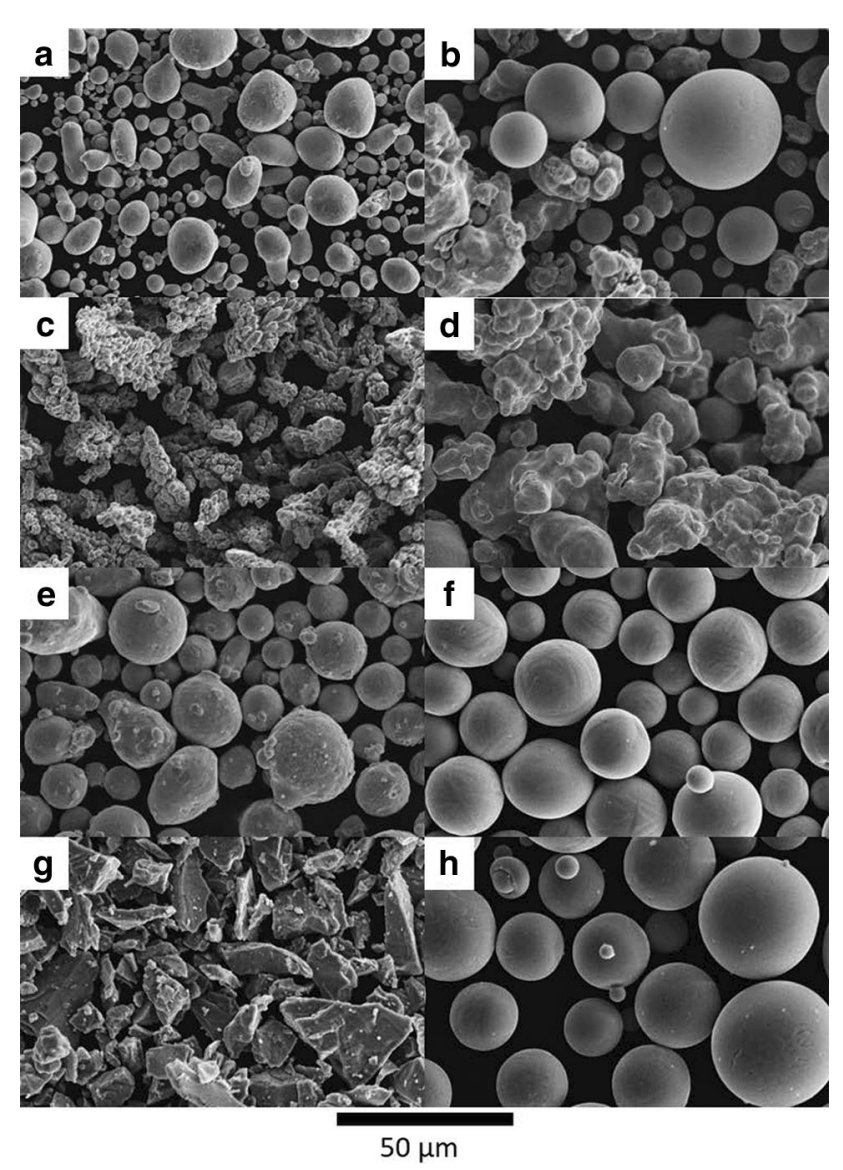

Fig. 2 SEM images of the feedstock powders: (a) $\mathrm{Sn}$, (b) $\mathrm{Cu}$, (c) $\mathrm{Cu}$ IR, (d) Fe, (e) SS316L, (f) Ti-SP, (g) Ti-AG, (h) Ti6Al4V

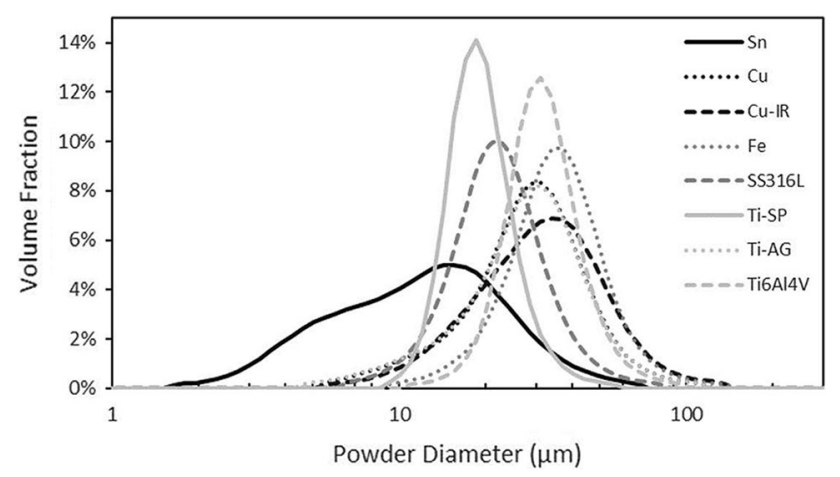

Fig. 3 Particle size distribution of the feedstock powders

metallographic finish and using a Clark CM-100AT Microhardness Tester (Sun-Tec, Novi, USA) for a penetration time of $15 \mathrm{~s}$ under a load of $10 \mathrm{gf}$ on 10 well-spaced areas. The error given for the hardness values corresponds to the standard deviation of the measurements. Tin had the overall lowest hardness $\left(8 \pm 1 \mathrm{HV}_{0.01}\right)$, while copper and iron had hardness values of $32-89 \mathrm{HV}_{0.01}$. The stainless steel 316L, titanium and Ti6Al4V powders had hardnesses that were greater than those previously studied with values reaching $340 \mathrm{HV}_{0.01}$ for Ti6Al4V. By comparison, the hardness values of copper and iron were on par with the aluminum and aluminum alloy powders from previous work (Ref 46).

\section{Kinetic Energy Estimations}

The particle velocity from its injection location up to its impact on the substrate is determined accordingly in two steps: first, complete 2D axisymmetric compressible flow simulations of the nozzle were carried out using SU2, then followed by particle tracking simulations using the oneway coupled Particle CFD module of CSAM Digital Solutions, a software developed within the Cold Spray Additive Manufacturing (CSAM) industrial R\&D group led by the National Research Council of Canada (Ref 53). The numerical simulation takes into account the complex shock substrate interaction and the influence of the bow shock on the particle trajectory. This model allows the calculation of the particle velocity for each cut of the particle size distribution of the feedstock powders and it considers all particles to be spherical.

The kinetic energy of a particle can be estimated through Eq 1:

$E_{C_{1 \text { particle }}}=\frac{1}{2} m v_{\text {part }}^{2}=\frac{1}{2} * \rho_{\text {part }} * \frac{4}{3} \pi r_{\text {part }}^{3} * v_{\mathrm{p}}^{2}$

where $E_{C, 1 \text { particle }}$ is the kinetic energy of a particle, $\mathrm{m}$ is the mass of the particle, $v_{\mathrm{p}}$ is the particle velocity upon impact with the substrate, $\rho_{\text {part }}$ is the density of the $\mathrm{SC}$, and $r_{\text {part }}$ is the particle radius. For the purpose of the estimations conducted in this paper, all particles are assumed to be spherical.

Powders are described by a distribution of sizes (cuts on the particle size distribution), so the average particle energy is considered in this study, and calculated through Eq 2:

$E_{C}=\sum_{i}\left(f_{i *} E_{C_{1 \text { particle }}}\left(r_{i}\right)\right)=\frac{1}{2} * \rho_{\text {part }} * \frac{4}{3} \pi \sum_{i}\left(f_{i} r_{i}^{3} v_{i}^{2}\right)$

where $E_{\mathrm{C}}$ is the average particle energy, $r_{i}$ is the radius of a particle of a cut (range) noted $i, f_{i}$ is the fraction of particles in the cut $i$, and $v_{i}$ is the velocity of the particles in the cut $i$. The average particle impact energies are regrouped in Fig. 4. As with the choice of SC properties, it can be seen that a wide spread of particle impact energies is also obtained. With values between $1 \times 10^{-6} \mathrm{~J}$ and $8 \times 10^{-6} \mathrm{~J}$, it appears that the impact energy of the SC particles from this study are higher than the energy of the Al/Al-alloy particles from (Ref 46) $\left(1 \times 10^{-6} \mathrm{~J}\right.$ to $\left.3 \times 10^{-6} \mathrm{~J}\right)$. The tin in this study has a lower average impact energy compared than the tin from the previous study $\left(1.32 \times 10^{-6} \mathrm{~J}\right.$ 
compared to $2.28 \times 10^{-6} \mathrm{~J}$ ): this is due to the tin from the previous study having a small fraction of large powders (above $70 \mu \mathrm{m}$ ) that the tin in this work does not have. It is also important to note that the average particle velocity for particles of irregular morphology (Cu-IR, Ti-AG, Fe) may be higher, due to higher drag coefficients (Ref 51,54), such that their kinetic energy may also be higher.

\section{Substrates}

The substrates used in this work were epoxy-CFRPs provided by Bombardier Aerospace (Montreal, Canada), Polyether-Ether-Ketone (PEEK)-CFRPs provided by TenCate (Netherlands) and commercially available 1020 mild steel plates. The CFRP substrates are presented in the previous work (Ref 46). The steel substrates were used as a benchmark to compare the spraying of powders on CFRPs to a typical metal-metal cold spraying situation. The epoxy-CFRPs (abbreviated as e-CFRP) used here consists of a thermosetting epoxy matrix with continuous carbon fiber reinforcements. The e-CFRP panels were made of four plies of epoxy/carbon fiber prepreg ([0/90]2s) and have various coating finishes prepared by the manufacturer: a bare finish, a putty finish, and a surface film finish (that could be described as a fine-squared mesh finish on the substrate). The bare finish e-CFRP is the as-manufactured substrate, the putty e-CFRP includes a surface finished with a pinhole filler and surfacer to produce defectfree surfaces and the surface film e-CFRP includes a neat epoxy resin film with an embedded veil, normally a mat, on the top surface, to help handling the resin film. The hardness of these substrates was measured as per the powders, and the values are $39 \pm 8 \mathrm{HV}_{0.01}$ for the bare e-CFRP,

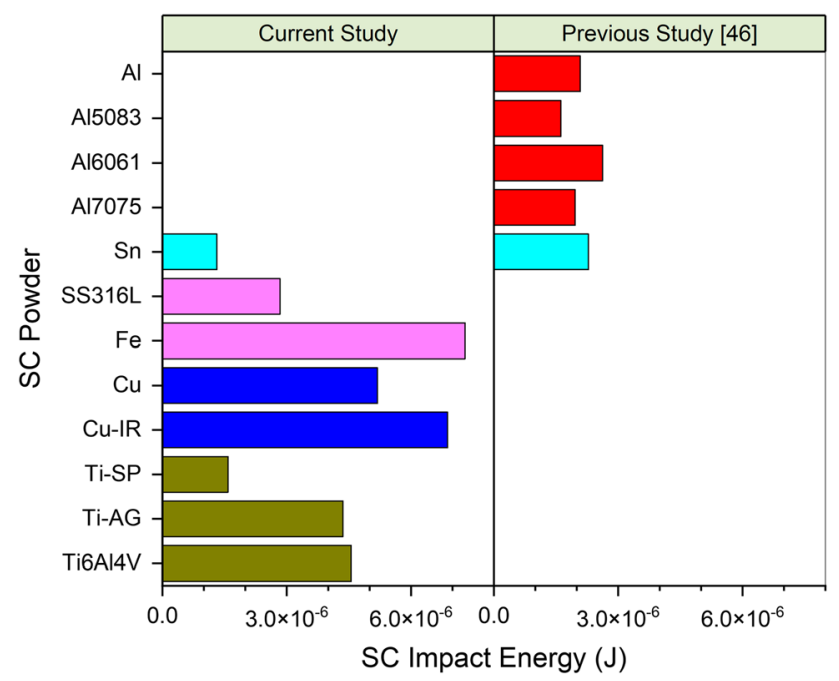

Fig. 4 Kinetic energy of the various powders of this study and of the $\mathrm{Al} / \mathrm{Al}$ alloy powders used in (Ref 46). Bar color is based on SC density
$51 \pm 15 \mathrm{HV}_{0.01}$ for the putty e-CFRP and $40 \pm 13 \mathrm{HV}_{0.01}$ for the surface film e-CFRP. The PEEK-CFRP used here consists of a thermoplastic polyether-ether-ketone matrix with continuous carbon fiber reinforcements. These panels were made of five plies of PEEK/carbon fiber $([(0,90) 2 /$ $(0,90) 3 R])$. The hardness of this substrate was differentiated between areas showing superficially pure PEEK, and superficially predominant carbon fibers. The respective hardness values for each area are $26 \pm 3 \mathrm{HV}_{0.01}$ and $63 \pm 22$ $\mathrm{HV}_{0.01}$. For all CFRP substrates, the thickness of the polymeric layer would vary accordingly with the weave of the carbon fiber mesh and would be between $<1$ and $50 \mu \mathrm{m}$ at the top surface of the substrate. Sheet sections of dimensions $7 * 7 \mathrm{~cm}$ were used as substrates during the cold spray campaigns. The substrates were degreased with ethanol, and the mild steel plates were grit-blasted with 24 grit alumina before cold spraying. The CFRP substrates were not grit-blasted as it would result in the erosion of the substrate.

\section{Cold Spray Conditions}

The cold spraying was performed at the McGill-NRC cold spray facility at National Research Council of Canada in Boucherville, using a low pressure commercially available CenterLine SST SSM-P3300 system (Supersonic Spray Technologies, CenterLine Windsor Limited, Canada) and a \#440-00125 standard straight, round, stainless-steel nozzle. This system uses a down-stream, radial powder injection, where particles are injected after the throat of the nozzle thus reducing risks of nozzle clogging. The primary cold spray parameters are listed in Table 2. These parameters

Table 2 Principal cold spray parameters

\begin{tabular}{ll}
\hline Powder & Sn \\
& Sn-10Cu \\
& Sn-10Cu-IR \\
& Sn-10Fe \\
& Sn-10SS316L \\
& Sn-10Ti-SP \\
& Sn-10Ti-AG \\
& Sn-10Ti6Al4V \\
Substrate & Steel \\
& e-CFRP: \\
& Bare \\
& Putty \\
Carrier gas temperature $\left({ }^{\circ} \mathrm{C}\right)$ & Surface film \\
Gas pressure (psi/MPa) & PEE-CFRP \\
\hline
\end{tabular}


were chosen based on previously successful cold spray campaigns with tin (Ref 18, 45, 46, 55) and at the selected conditions, melting was observed in previous work (Ref 18, 45, 55). A comparison between cold spraying pure tin and the powder mixtures with SCs of varying properties was thus possible, on a variety of CFRP substrates. The carrier gas was nitrogen, the standoff distance was $18 \mathrm{~mm}$, the step size was $1 \mathrm{~mm}$ with 38 steps, and the gun travel speed was $25 \mathrm{~mm} / \mathrm{s}$. The powder feed rate was set to 1 revolution per minute (RPM), which gave a measured feeding rate between 10.1 and $16.9 \mathrm{~g} / \mathrm{min}$, measured every three sprays to accurately assess the variation. The substrates were pre-heated by operating a single pass without powder feeding, at the given conditions (Table 2), then, only one pass was sprayed for each set of conditions. With this procedure, the acquired results would be meaningful as the average DE from a large spray area is acquired, and the study is focused on trends rather than absolute values. All the substrates were aligned and sprayed at the same time for one condition, so that any external variation (e.g. feeding, temperature effects) may be neglected.

\section{Result Analysis}

After the cold spray process, the samples were observed from a top surface view, then prepared as metallographic samples and characterized with a Hitachi (Japan) SU3500 scanning electron microscope. The cross-sectional samples were cut (Delta Abrasimet, Buehler, Illinois, USA) and observed parallel to the spraying direction. The hardness of the tin in these samples was also measured. The SC retention rates (i.e. weight fractions of $\mathrm{SC}$ in the coatings) were estimated, by measuring the relative areas of tin and SC in 10 different SEM BSE-COMP images using an image analysis method, then converting the obtained volume fractions into weight fractions with Eq 3

$r_{\mathrm{SC}}=\%_{\mathrm{wt}_{\mathrm{SC}}}=\frac{1}{1+\frac{\rho_{\mathrm{Sn}}}{\rho_{\mathrm{SC}}} \frac{\left(1-\% v_{\mathrm{SC}}\right)}{\% v_{\mathrm{SC}}}}$

where $r_{\mathrm{SC}}$ is the retention rate of the SC, $\%_{\mathrm{wt}}$ is the weight fraction, $\%_{\mathrm{V}}$ is the volume fraction, and $\rho_{\mathrm{Sn}}$ and $\rho_{\mathrm{SC}}$ are respectively the densities of tin and of the SC.

Deposition efficiency was measured as the mass gain of the substrate divided by the total mass of feedstock powder fed during the time the gun was over the substrate. The relative DE of each coating element could be determined from the weight fractions determined with $\mathrm{Eq} \mathrm{3}$, as described in (Ref 55). The expression are recalled in Eqs 4 and 5 .
$\mathrm{DE}_{\mathrm{SC}}=\frac{r_{\mathrm{SC}} * \mathrm{DE}}{0.1}$

$\mathrm{DE}_{\mathrm{Sn}}=\frac{\left(1-r_{\mathrm{SC}}\right) * \mathrm{DE}}{0.9}$

where $\mathrm{DE}, \mathrm{DE}_{\mathrm{SC}}$ and $\mathrm{DE}_{\mathrm{Sn}}$ are respectively the overall $\mathrm{DE}$ of the coating, pure SC and pure Sn.

\section{Results}

The top surface views of the samples showed continuous coatings for most mixtures and substrates, and no peeling was observed, unlike in the previous study (Ref 46). Looking into more detail, deposition seemed uniform on all steel, bare e-CFRP and surface film e-CFRP (Fig. 5a), while deposition on putty e-CFRP and PEEK-CFRP presented more irregularity (visible waviness on the surface and/or visible areas of underlying carbon fibers) (Fig. 5b). Only one set of conditions provided a discontinuous surface coating (Sn-10Ti6Al4V on PEEK-CFRP) (Fig. 5c).

The hardness of the tin in the coatings was measured and found to be between $12 \pm 1 \mathrm{HV}_{0.01}$ and $14 \pm 1 \mathrm{HV}_{0.01}$, which means that the average hardness of tin in the coatings was $50-75 \%$ higher than the hardness of the pure tin feedstock powders. This was true regardless of the presence of SC in the feedstock powder, and regardless the choice of this SC. Despite the fact that tin particles may have experienced melting, this would then indicate that there is still some work hardening effect, which is, however, not promoted by the addition of hard SC particles.

The retention rates of the SC are presented in Table 3 with typical micrographs of corresponding coating cross sections presented in Fig. 6.

SC retention varies greatly: Ti-SP and Ti6Al4V had retention rates close to $0 \%$ while retention rates of $3-5 \%$ were observed for SC Fe, and even 17-25\% for $\mathrm{Cu}-\mathrm{IR}$. This range for $\mathrm{Cu}-\mathrm{IR}$ is well beyond the $10 \%$ in the initial feedstock powder and resulted in SC DE values between 37 and $71 \%$ (Table 3 ). This result would suggest that $\mathrm{Cu}-\mathrm{IR}$ is accumulating in the coating at the expense of $\mathrm{Sn}$ (as seen in Fig. 6c), i.e. $\mathrm{Cu}-\mathrm{IR}$ retention would increase as the $\mathrm{Sn}$ retention decreases.

Pure Sn has a DE of 20-22\% on the CFRP substrates (Table 3). Mixtures with SC Fe, SS316L and Ti/Ti6Al4V all generate overall DE values that are relatively lower than the DE of single component Sn powder (11-19\%), with the lowest values being generally obtained on the putty e-CFRP or the PEEK-CFRP. By establishing the SC DE from the retention rates with $\mathrm{Eq} 3$, it is possible to determine the effective pure Sn DE for each coating (Ref 55). Even with the improvements brought by the addition of the SC for the Sn DE compared to the overall DE, the effective 


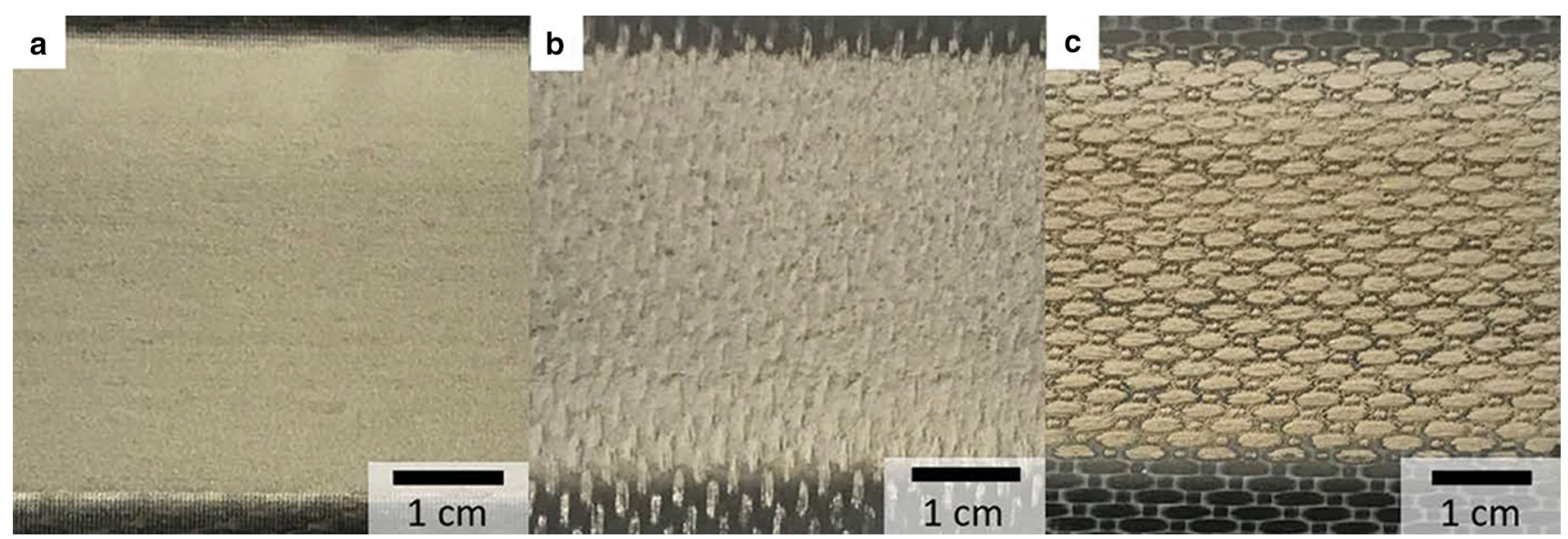

Fig. 5 Top surface images of various coatings: (a) Sn-10Fe on bare e-CFRP, (b) Sn-10SS316L on putty e-CFRP, (c) Sn-10Ti6Al4V on PEEKCFRP

Sn DE in these coatings only reaches the average DE of single component tin coatings in one occurrence (Sn-10TiSP sprayed onto surface film e-CFRP). SC Cu, on the other hand, lead to slight improvements of the effective Sn DE as compared to pure Sn coatings on CFRP (from 20-22\% to $22-25 \%$ ), while $\mathrm{SC} \mathrm{Cu}$-IR provided coatings with a comparable overall DE (20-23\%), but an effective Sn DE below that of the pure Sn coatings (from 20-22\%, to $17-20 \%$ ).

Similar observations can be noted on the steel substrates, where the pure Sn coating has a DE of $41 \%$, while the SC Fe, SS316L and Ti/Ti6Al4V provide overall DE values that are slightly lower (37-38\%). The improvement brought by these SC allow the effective Sn DE to be around $40-42 \%$, which is more on par with the pure Sn coatings on steel, in contrast to what was observed on the CFRP substrates. Again, $\mathrm{SC} \mathrm{Cu}$ provides a slight improvement of the Sn DE (44\%, up from 41\%), while SC Cu-IR, although showing a similar overall DE of $42 \%$, results in a lower effective Sn DE of $39 \%$.

Therefore, it appears that most of the SC of this study generate a decrease of pure Sn DE on the CFRP substrates (Fe, SS316L, Cu-IR, Ti-SP, Ti-AG, Ti6Al4V), while SC $\mathrm{Cu}$ generates a slight increase of the pure Sn DE. These comparisons of overall DE and pure Sn DE may not provide notable differences in absolute value (one may consider the values are rather similar in front of measurement errors imposed by powder fluctuations), but certain trends do seem to appear nevertheless, which can provide some value. Furthermore, the retention rates of these SC vary greatly with some particles showing close to no retention versus others that are highly retained. These results could be a combination of factors and will therefore be discussed comparatively to the SC properties, to establish potential trends between pure Sn DE and SC choice.

\section{Discussion}

\section{On the Effect of Individual SC Properties}

As shown above, the SC of this study only rarely improve the DE of pure Sn on CFRP, and retention rates were observed to vary from 0 to $25 \%$. On the other hand, in previous work, $\mathrm{Sn}$ was mixed with $\mathrm{Al}$ or $\mathrm{Al}$ alloys and cold sprayed at the same conditions: improvements of pure $\mathrm{Sn}$ $\mathrm{DE}$ were quite strong (from 11 to $17 \%$ to a range of $18-27 \%$ with the $\mathrm{SC} \mathrm{Al} / \mathrm{Al}$ alloy), and it was observed that SC retention was below $1 \%$, compared to the initial $10 \%$ in the feedstock powder (Ref 46). Given spraying conditions and substrates were the same, this naturally leads to exploring the different SC properties that could explain the varying effects on both $\mathrm{SC}$ retention and DE of tin. The effects of each SC property are summarized in Table 4: this table takes into account results obtained in this work and in previous work (Ref 46).

\section{SC Hardness}

$\mathrm{Cu}$ and $\mathrm{Cu}$-IR offer a hardness value within the range of the substrate hardness (i.e. 25-65 $\mathrm{HV}_{0.01}$ ), while Fe, SS316L, $\mathrm{Ti}, \mathrm{Ti}-\mathrm{AG}$ and Ti6Al4V have hardness values that are greater than $80 \mathrm{HV}$. As previously discussed, overall $\mathrm{DE}$ of the coatings with each of the latter SC group is slightly lower than the $\mathrm{DE}$ of a pure tin coating, while $\mathrm{SC} \mathrm{Cu} / \mathrm{Cu}-$ IR offer a slight increase as compared to pure tin. Most noticeably, SC SS316L and Ti6Al4V present the highest SC hardness values (215 and $340 \mathrm{HV}$, respectively), but also the lowest overall DE values on CFRP (11-17\% vs 20-22\% for pure Sn coatings): Sn-10Ti6Al4V on PEEKCFRP is also a rare "poor" coating in this study (Fig. 5c), 
Table 3 Retention rates of the $\mathrm{SC}$ measured at the cross sections of the coatings on various substrates, and calculated deposition efficiencies for the SC and tin in the coatings

\begin{tabular}{|c|c|c|c|c|c|}
\hline \multirow[t]{2}{*}{ Powder } & \multirow[t]{2}{*}{ Substrate } & \multirow{2}{*}{$\begin{array}{c}\text { Weight fraction of SC } \\
\qquad(\%)\end{array}$} & \multicolumn{3}{|c|}{ Deposition efficiency (\%) } \\
\hline & & & Overall & $\mathrm{SC}$ & $\mathrm{Sn}$ \\
\hline \multirow[t]{5}{*}{ Sn } & Bare e-CFRP & $\cdots$ & 21 & $\ldots$ & 21 \\
\hline & Putty e-CFRP & $\ldots$ & 21 & $\ldots$ & 21 \\
\hline & Surface Film e-CFRP & $\ldots$ & 22 & $\ldots$ & 22 \\
\hline & PEEK-CFRP & $\ldots$ & 20 & $\ldots$ & 20 \\
\hline & Steel & $\ldots$ & 41 & $\ldots$ & 41 \\
\hline \multirow[t]{5}{*}{$\mathrm{Sn}-10 \mathrm{Cu}$} & Bare e-CFRP & 1 & 23 & 3 & 25 \\
\hline & Putty e-CFRP & 1 & 23 & 2 & 25 \\
\hline & Surface Film e-CFRP & 2 & 22 & 4 & 24 \\
\hline & PEEK-CFRP & 2 & 20 & 4 & 22 \\
\hline & Steel & $\approx 0$ & 40 & 2 & 44 \\
\hline \multirow[t]{5}{*}{ Sn-10Cu-IR } & Bare e-CFRP & 20 & 23 & 46 & 20 \\
\hline & Putty e-CFRP & 20 & 20 & 40 & 17 \\
\hline & Surface Film e-CFRP & 25 & 23 & 57 & 19 \\
\hline & PEEK-CFRP & 17 & 21 & 37 & 19 \\
\hline & Steel & 17 & 42 & 71 & 39 \\
\hline \multirow[t]{5}{*}{$\mathrm{Sn}-10 \mathrm{Fe}$} & Bare e-CFRP & 5 & 18 & 9 & 19 \\
\hline & Putty e-CFRP & 3 & 15 & 4 & 16 \\
\hline & Surface Film e-CFRP & 5 & 19 & 10 & 20 \\
\hline & PEEK-CFRP & 3 & 17 & 5 & 18 \\
\hline & Steel & 3 & 37 & 10 & 40 \\
\hline \multirow[t]{5}{*}{ Sn-10SS316L } & Bare e-CFRP & 2 & 16 & 3 & 17 \\
\hline & Putty e-CFRP & 2 & 12 & 2 & 13 \\
\hline & Surface Film e-CFRP & 3 & 17 & 5 & 18 \\
\hline & PEEK-CFRP & 2 & 16 & 3 & 17 \\
\hline & Steel & 1 & 37 & 3 & 41 \\
\hline \multirow[t]{5}{*}{ Sn-10Ti-SP } & Bare e-CFRP & $\approx 0$ & 18 & $\approx 0$ & 20 \\
\hline & Putty e-CFRP & $\approx 0$ & 17 & $\approx 0$ & 19 \\
\hline & Surface Film e-CFRP & $\approx 0$ & 19 & $\approx 0$ & 21 \\
\hline & PEEK-CFRP & $\approx 0$ & 13 & $\approx 0$ & 14 \\
\hline & Steel & $\approx 0$ & 38 & $\approx 0$ & 42 \\
\hline \multirow[t]{5}{*}{ Sn-10Ti-AG } & Bare e-CFRP & 3 & 17 & 6 & 18 \\
\hline & Putty e-CFRP & 4 & 14 & 5 & 15 \\
\hline & Surface Film e-CFRP & 4 & 19 & 7 & 20 \\
\hline & PEEK-CFRP & 4 & 15 & 6 & 16 \\
\hline & Steel & 2 & 37 & 8 & 40 \\
\hline \multirow[t]{5}{*}{ Sn-10Ti6Al4V } & Bare e-CFRP & $\approx 0$ & 16 & $\approx 0$ & 18 \\
\hline & Putty e-CFRP & $\approx 0$ & 15 & $\approx 0$ & 17 \\
\hline & Surface Film e-CFRP & $\approx 0$ & 17 & $\approx 0$ & 19 \\
\hline & PEEK-CFRP & $\approx 0$ & 11 & $\approx 0$ & 12 \\
\hline & Steel & $\approx 0$ & 38 & $\approx 0$ & 42 \\
\hline
\end{tabular}

suggesting that relatively harder particles have detrimental effects on the deposition process. Typically, these negative effects could be explained by the erosion of previously deposited Sn particles by the harder SCs, and this will be discussed further in the second section of the discussion.
The current results also seem to support the previous study where the existence of an optimal SC hardness value for pure Sn DE was suggested for powder hardnesses in the range of the substrate hardness (Ref 46$)$. 


\section{SC Morphology}

The more spherical powders of this study (Ti-SP, Ti6Al4V, $\mathrm{Cu}, \mathrm{SS316L})$, as well as the $\mathrm{Al} / \mathrm{Al}$ alloys from (Ref 46$)$,

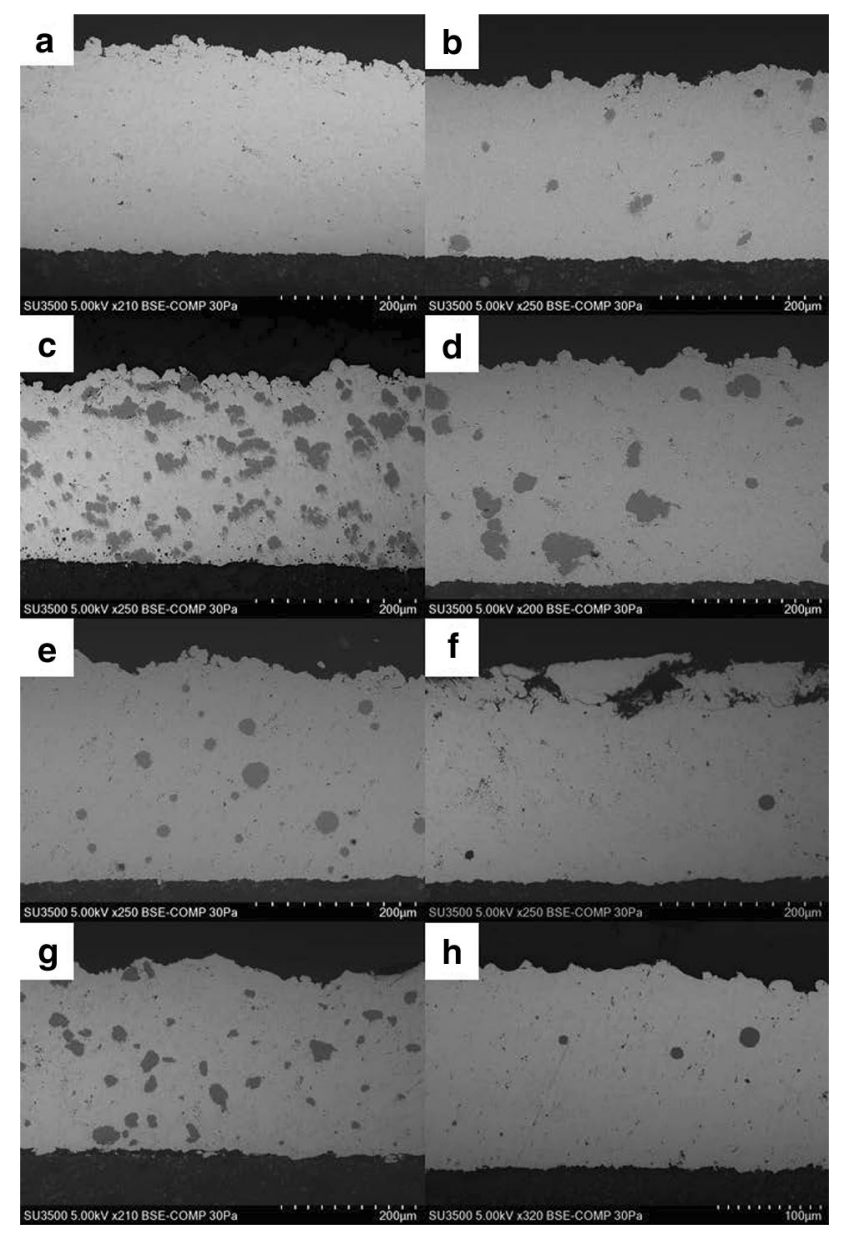

Fig. 6 SEM-BSE images of the cross-sectional microstructures for various coatings on the surface film e-CFRP: (a) Sn, (b) $\mathrm{Sn}-10 \mathrm{Cu}$, (c) Sn-10Cu-IR, (d) Sn-10Fe, (e) Sn-10SS316L, (f) Sn-10Ti-SP, (g) Sn-10Ti-AG, (h) Sn-10Ti6Al4V. Particles with darker contrast in the coatings are the SC particles (Sn having the highest atomic number) resulted in very low retention values (below $3 \%$ ) and as an effect, these coatings presented SC DE values below $5 \%$. The powders with more irregular morphologies $(\mathrm{Fe}$, Ti$\mathrm{AG}, \mathrm{Cu}-\mathrm{IR}$ ) offered the greatest retention values, with $\mathrm{Cu}$ IR offering the highest values (17-25\%). These results support the works of Che et al. (Ref 45) where they suggested that use of irregular SC morphologies leads towards more $\mathrm{SC}$ retention as there is more mechanical interlocking compared to spherical morphologies. Since irregular powders have higher drag coefficients, they could also have higher velocities than their spherical counterparts (Ref $51,54)$, which could also explain the higher rate of embedding.

While irregular SCs seem to lead to an increased retention of the SC, spherical SCs seem to lead to greater improvements in Sn DE: as previously mentioned, both copper SCs generate a slight increase in overall DE on CFRP as compared to the pure $\mathrm{Sn}$ coatings, but $\mathrm{Cu}-\mathrm{IR}$ results in lower effective pure $\mathrm{Sn} D E$ than in the pure $\mathrm{Sn}$ coatings, while $\mathrm{Cu}$ leads to an overall improvement. This could be related to peening of tin by the spherical SC during deposition, while the irregular SC seems to take the place of the tin in the coating through increased embedding.

\section{SC Density}

When considering SC density, it is more difficult to establish a clear trend regarding overall $\mathrm{DE}$ and pure $\mathrm{Sn}$ DE. Al/Al alloys provided the greatest improvements in overall DE and Sn DE (Ref 46) and these SC were the lowlevel density of this study $\left(\sim 2.7 \mathrm{~g} \mathrm{~cm}^{-3}\right)$. SC Cu led to similar improvements, albeit of smaller amplitude (from $20-22 \%$ to $22-25 \%$ ): $\mathrm{Cu}$ has a density of $8.96 \mathrm{~g} . \mathrm{cm}^{-3}$, which would be the high-level of the study that is being conducted. On the other hand, $\mathrm{Ti}$ and $\mathrm{Fe}$, as well as their corresponding alloys, have densities respectively of 4.5 $\mathrm{g} \mathrm{cm}^{-3}$ and $7.9 \mathrm{~g} \mathrm{~cm}^{-3}$, and their use as SC has generated

Table 4 Effect of each SC property on overall DE, DE of pure tin and SC DE

\begin{tabular}{|c|c|c|c|c|}
\hline SC property & Value/trend & Overall DE & Pure tin DE & SC DE \\
\hline \multirow[t]{4}{*}{ Hardness } & Low ( $\sim$ hardness of substrate) & Greatly increased (Al, Al alloy) & Greatly increased (Al, Al alloy) & $\ldots$ \\
\hline & & Slight increase $(\mathrm{Cu}, \mathrm{Cu}-\mathrm{IR})$ & Slight increase $(\mathrm{Cu})$ & \\
\hline & & Slight decrease $(\mathrm{Cu}-\mathrm{IR}, \mathrm{Fe})$ & Slight decrease (Cu-IR, Fe) & \\
\hline & High & Decreased & Decreased & $\ldots$ \\
\hline \multirow[t]{2}{*}{ Morphology } & Spherical & $\ldots$ & Slight increase & Low \\
\hline & Irregular & $\ldots$ & Slight decrease & High \\
\hline Density & Increasing & $\ldots$ & $\cdots$ & (Increase?) \\
\hline Median Size $\left(\mathrm{D}_{50}\right)$ & Any & $\ldots$ & $\ldots$ & $\ldots$ \\
\hline
\end{tabular}

An empty area indicates "no direct correlation" 
a decrease in overall DE and DE of pure Sn on CFRP. The density of $\mathrm{Sn}$ is $7.27 \mathrm{~g} \mathrm{~cm}^{-3}$, therefore indicating that $\mathrm{SC}$ with densities higher or lower than Sn, could either have a positive or negative effect on the DE: this would clearly indicate that any direct correlation of DE with density is not possible.

On another note, the higher retention rates of $\mathrm{SC} \mathrm{Fe}$, TiAG, $\mathrm{Cu}$-IR seem to follow the density of the SCs: in increasing order of density, Ti has a retention of 2-4\% (SC $\mathrm{DE}$ of $5-8 \%$ ), while $\mathrm{Fe}$ has a retention of 3-5\% (SC DE of 4-10\%), and finally $\mathrm{Cu}$ has a density of $8.96 \mathrm{~g} \mathrm{~cm}^{-3}$ and a retention of $17-25 \%$, (SC DE of $37-71 \%$ ). This observation would correlate well with the idea that higher density results in higher kinetic energy, and therefore higher penetration and mechanical restraint in a relatively softer $\mathrm{Sn}$ matrix. However, this observation could also be explained by the different morphologies of these powders (dendritic powders having more surface area than angular powders), rendering the mechanical restraint easier to initiate for dendritic powders, as discussed in (Ref 45).

\section{SC Particle Size}

From the sole stand point of the $\mathrm{SC} \mathrm{D}_{50}$, it seems that the SC Al/Al alloy of the previous study had generally smaller particle size distributions ( $D_{50}$ between 16 and $22 \mu \mathrm{m}$ ) (Ref 46) while the SCs of this study had relatively larger particle size distributions ( $\mathrm{D}_{50}$ between 20 and $37 \mu \mathrm{m}$ ), so it could have been assumed that the improvements brought by SC $\mathrm{Al}$ and its corresponding alloys could be associated with a more ideal, smaller particle size distribution. Nevertheless, Ti-SP has a median size of $20 \mu \mathrm{m}$ and a density relatively close to that of $\mathrm{Al}$ as compared to $\mathrm{Sn}$, and while $\mathrm{Al}$ brings improvements in overall DE and effective DE of pure Sn, Ti-SP does not.

This finally leads to approaching the results from the perspective of the kinetic energy of the impinging powders, and therefore correlating the effects of particle size, density and particle velocity (which is impacted by morphology (Ref 51, 54)) to estimate the energy of each SC upon impact on the substrate, but also on Sn particles once they have been deposited.

\section{On the Effect of SC Kinetic Energy}

The effect of the SC on the pure Sn DE is shown in Fig. 7 as a function of the SC hardness and of the SC impact energy. In contrast to the study of each individual property, clearer trends are apparent.

Low hardness SC impacting the substrate at low impact energy, such as $\mathrm{Al}$ or Al alloys, lead to notably positive improvements of Sn DE on CFRP (+ 9-15\%), while SC with higher impact energies, such as $\mathrm{Cu}$ and $\mathrm{Fe}$, lead to more neutral effects on the $\mathrm{Sn} \mathrm{DE}: \mathrm{Cu}$ has a slightly positive effect $(+3 \%)$, and $\mathrm{Cu}-\mathrm{IR} / \mathrm{Fe}$, with the highest impact energies of this study, have more of a negative effect $(-3 \%)$. This evolution of Sn DE with low hardness and increasing impact energy seems to evolve with a linear trend and it seems that, below $6 \times 10^{-6} \mathrm{~J}$, the SC improves the Sn DE as compared to the cold spraying of pure Sn, while higher impact energies lead to a decrease of Sn DE. Schmidt et al. (Ref 56) calculated the erosion velocity of $\mathrm{Sn}$ as being equal to around $350 \mathrm{~m} / \mathrm{s}$ for a $25 \mu \mathrm{m}$ particle, and by using Eq 1, this corresponds to an impact energy of $3.6 \times 10^{-6} \mathrm{~J}$. The particle tracking simulation allows the calculation of the particle impact velocity for each cut of the measured particle size distribution, which, in turn, allows a particle kinetic energy distribution to be established. Table 5 presents the proportion of each feedstock powder below or above the erosion energy of Sn $(3.6 \times$ $10^{-6} \mathrm{~J}$ ); it can be seen that $\mathrm{Cu}$-IR and $\mathrm{Fe}$ have a higherthan-average proportion of particles with an erosive effect (54 and 68\%, respectively), while $\mathrm{Cu}$ has fewer particles that could exhibit an erosive behavior (46\%).

It is also important to notice that $\mathrm{Cu}-\mathrm{IR}$ and $\mathrm{Fe}$ have irregular morphologies. Wong et al. (Ref 51) provided results that showed that irregular titanium had an average velocity $15 \%$ higher than the velocity of the spherical powder with a similar average particle size. Therefore, by factoring in such a difference, it can be suggested that as high as $66 \%$ of $\mathrm{Cu}-\mathrm{IR}$ and $82 \%$ of $\mathrm{Fe}$ could exhibit an erosive behaviour, thus further explaining the decrease in Sn DE obtained as a result of their use as SC. The obtained energy of $6 \times 10^{-6} \mathrm{~J}$ for relative neutral effect on Sn DE at low hardness (as compared to the calculated erosive energy of $3.6 \times 10^{-6} \mathrm{~J}$ ) could be a trade-off between the proportion of erosive SC, and the fact that $90 \mathrm{wt} . \%$ of the sprayed powder is pure $\mathrm{Sn}$ that can deposit on CFRP. Therefore, it is possible that the erosive effect of the SC only appears at higher impact energies.

In any case, the previous low-hardness observations would suggest that the SC can provide improved deposition when the SC hardness is on par with that of the substrate (as advanced in the previous study (Ref 46), and supported in this work) and when SC impact energy is low or on par with that of the Sn feedstock powder. Furthermore, with low SC hardness and higher SC impact energy, the benefits of the enhanced "crack-filling" mechanism (Ref 46) would be lost to increasing erosive behavior of the SC.

Another trend that appears from Fig. 7 is that higher hardness SC, such as Ti, SS316L and Ti6Al4V, consistently lead to a decrease of Sn DE as compared to the DE of pure tin, regardless of their impact energy (from $1.6 \times$ $10^{-6} \mathrm{~J}$ with Ti-SP to $4.6 \times 10^{-6} \mathrm{~J}$ with Ti6Al4V). The decrease of Sn DE also occurs regardless the low erosive behavior of some of these powders, such as Ti-SP which 
Fig. 7 Average pure Sn DE improvement for the various SCs, represented as a function of the SC hardness and impact energy. Sphere color is based on SC density

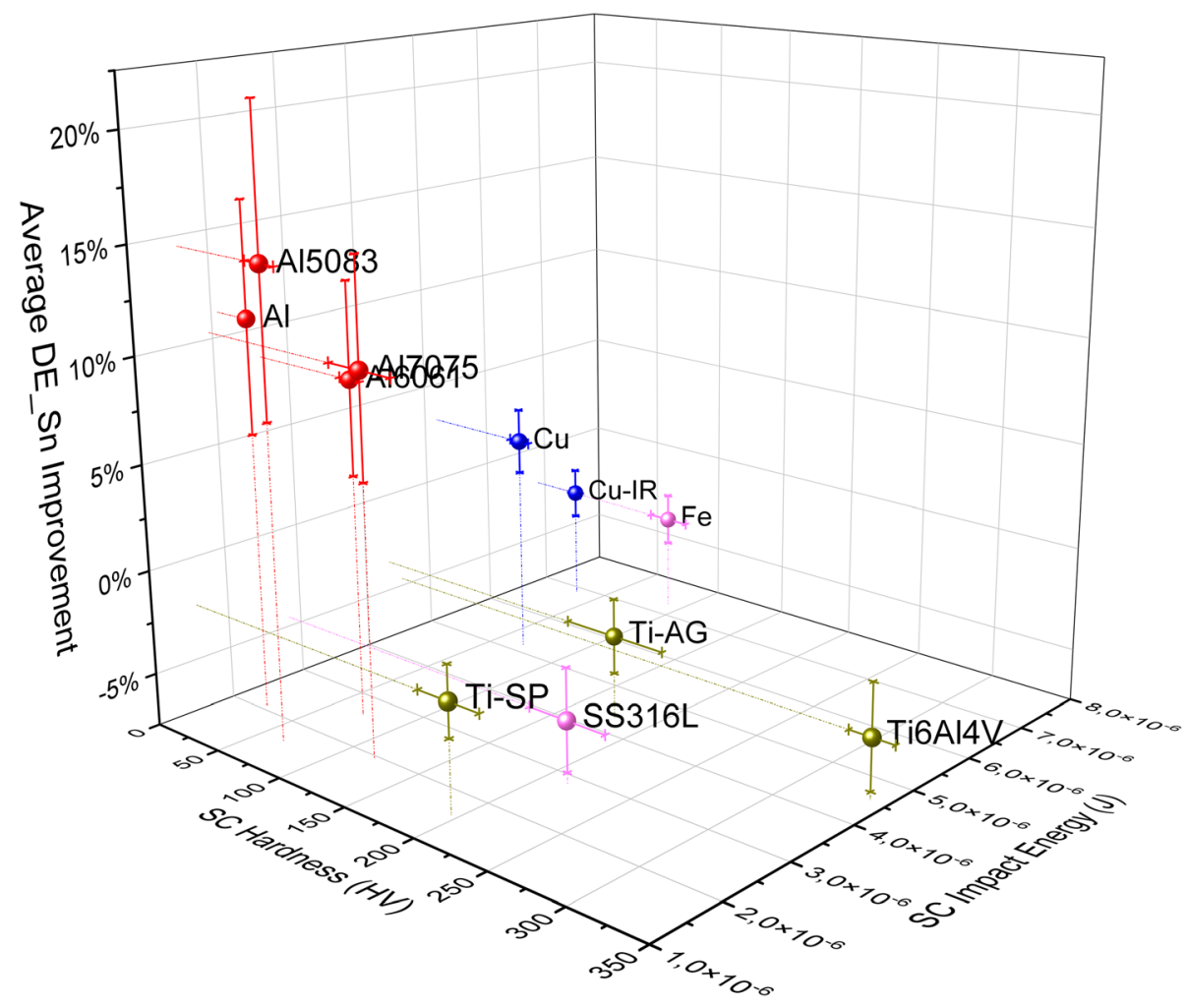

Table 5 Proportion of particles below or above the erosion energy of Sn, calculated from the information provided by (Ref 56) with Eq 2

\begin{tabular}{llcr}
\hline Reference & Powder & $\begin{array}{c}\text { Particles with impact energy } \\
\text { below } 3.6 \times 10^{-6} \mathrm{~J}(\%)\end{array}$ & $\begin{array}{c}\text { Particles with impact energy } \\
\text { above } 3.6 \times 10^{-6} \mathrm{~J}(\text { erosive behavior on Sn) }(\%)\end{array}$ \\
\hline Current study & Sn & 92 & 8 \\
& Cu & 54 & 54 \\
& Cu-IR & 46 & 68 \\
& Fe & 32 & 19 \\
SS316L & 81 & 4 \\
Previous study (Ref 46) & 96 & 37 \\
& Ti-SP & 63 & 44 \\
& Ti6Al4V & 56 & 11 \\
& Sn & 89 & 15 \\
& Al & 85 & 12 \\
& Al5083 & 88 & 21 \\
\hline
\end{tabular}

only has $4 \%$ of powders with an energy above $3.6 \times 10^{-6} \mathrm{~J}$ (Table 5). This may seem controversial as it could be expected that a combination of low kinetic energy and gradually increasing particle hardness would lead to a gradual appearance of erosion through peening or limited degrees of erosion from non-eroding powders, while these results would suggest rapid appearance of erosion (from +
$10 \%$ with $\mathrm{Al} 7075$ at $118 \mathrm{HV}_{0.01}$, to $-3 \%$ with $\mathrm{Ti}-\mathrm{AG}$ at $\left.178 \mathrm{HV}_{0.01}\right)$. A possible explanation is that the range of powder size distributions considered in this study is not small enough to obtain sufficiently low impact energies that could offset higher hardness values, and thus avoid erosion. 
Based on these observations, it would seem that deposition of tin is most improved when a SC is added with a hardness similar to the substrate and an impact energy on par or lower than the Sn powder. This combination of hardness and low impact energy could be the required elements to enhance the "crack-filling" mechanism, as was initially described in (Ref 18) for tin deposition on CFRP and further explained described in (Ref 46) for the role of the SC. These conditions could provide better first-layer Sn deposition, as suggested in (Ref 46) with $\mathrm{Al} \mathrm{5083,} \mathrm{without}$ eroding the coating during the build-up phase-in contrast to what is observed here with $\mathrm{Cu}$ or $\mathrm{Fe}$, which seem to be eroding the coating. This also reinforces the importance of considering the impact energy of powders when discussing the cold spraying of metallic particles onto CFRP, as initially mentioned by Lupoi et O'Neill (Ref 26): in this work, they defined a deposition window for impact energies below $2 \times 10^{-6} \mathrm{~J}$.

\section{Ramifications of SC Findings for the Deposition of Single Component Powders onto CFRP}

Metallization of CFRP via cold spray has been studied under various considerations over the past decade and it has proven to be relatively difficult to achieve given a variety of limitations. These limitations mainly concern most metals being too hard to deform and deposit without eroding the CFRP, which can also be viewed as the difficulty of achieving the critical velocity of the metallic powders without eroding the substrate (Ref 18, 26, 31). By considering the deposition of tin mixed with other metallic powders (i.e. SC), some insight into these limitations has been provided and they may be refined.

The previous study (Ref 46) revealed that an optimal SC hardness value seems to exist to enhance the "crack-filling" mechanism, and permit better deposition of Sn on CFRP. The current study supports this idea that powder hardness is a key factor in cold spraying CFRP, as notably higher hardness SCs lead to decreased pure Sn deposition (first section of the Discussion).The improved initiation of the "crack-filling" mechanism by the SC applies well to the deposition of $\mathrm{Sn}$, as single component $\mathrm{Sn}$ is too soft to generate sufficient cracks on its own, but the mechanism could be valid for any other single component metal susceptible of (1) generating its own cracks (i.e. hardness on par with the substrate hardness, according to (Ref 46)) and (2) deforming to fill the cracks (i.e. a metal in the range of its critical velocity). Therefore, single component powder candidates for deposition on CFRP would be materials such as $\mathrm{Sn}, \mathrm{Pb}, \mathrm{Al}, \mathrm{Cu}$ and $\mathrm{Zn}$ powders (or associated alloys with similar hardness levels). These results would also explain the difficulty to cold spray coatings with harder materials such as steel on CFRP, as observed elsewhere (Ref 27, 28).
Annealing harder alloys to spray them as softer materials could be an alternative. Based on the description of the "crack-filling" by Che et al. (Ref 18), thermal softening could lead to better filling of the micro-cracks through facilitated flow of material. Of course, directly lowering the hardness of the particles in the spray process, by increasing the temperature, is another solution. In previous studies at McGill University, the cold spraying of tin at temperatures above the melting point of tin $\left(300-320^{\circ} \mathrm{C}\right.$ vs $\left.232^{\circ} \mathrm{C}\right)$ led to some degree of melting (Ref $18,45,55)$, and while this was never proven to be a requirement for the "crack-filling" mechanism, it could be a metric indicating that sufficient thermal softening has been reached. Therefore, warm spraying (Ref 57) or high velocity air-fuel (HVAF) (Ref 58) could be interesting alternatives to be considered for improved sprayability of other metals such as $\mathrm{Cu}$ or $\mathrm{Al}$ on CFRP, and should be the focus of another study. Exploring this path may have the effect of diminishing some advantages of cold spray (i.e. heat damage and powder oxidation may increase), but these effects would still be relatively lower than other thermal spray techniques such as high velocity oxygen-fuel (HVOF) or plasma spray which use temperature of several thousand degrees (Ref 17).

This study also highlights the importance of the impact energy of the SC, for a hardness similar to that of the substrate. The role of SC impact energy in affecting the DE of pure Sn is also highlighted, as lower SC impact energies are suspected of allowing better activation of the CFRP, which in turn allows the "crack-filling" mechanism to occur (second section of the Discussion). In their study, Lupoi and O'Neill (Ref 26) had already mentioned the preference for using powders with lower impact energies to obtain deposition on CFRP, and by considering the existence of an ideal SC impact energy range, it could be suggested that this may apply to a single component powder as well (which would then act as its own SC). Therefore, the results from the current work can reinforce the kinetic energy limit that Lupoi et O'Neill described, around $2 \times 10^{-6} \mathrm{~J}$ (Ref 26).

This value of energy was presented as an average for several polymeric substrates (Ref 26), so it is important to note that the nature of the substrate could affect this value. Typically, it may be lower for CFRP, given the weaker nature of the interfacial adhesion strength between fibers and resin matrix (Ref 59,60), versus that of a bulk polymeric substrate. Furthermore, this criterion will probably vary depending on the deformation characteristics of the particles: with tin in this study, some thermal softening has been previously reported (Ref $18,45,55$ ), so the energy value could be higher. In any case, tin was deposited with an impact energy around $2 \times 10^{-6} \mathrm{~J}$, and the highest DEs were observed with $\mathrm{SC} \mathrm{Al}$ and $\mathrm{Al}$ alloys that had impact energies between $1 \times 10^{-6}$ and $3 \times 10^{-6} \mathrm{~J}$ (i.e. when the 
criterion was respected). Therefore, regardless the variation, the order of magnitude of the energy criterion described by Lupoi and O'Neill (Ref 26) seems valid.

\section{Additional Implications}

The results and discussion provided in this study focus on SC property effects on the deposition of Sn onto CFRP, and allowed some insight into requirements for deposition of single component materials onto CFRP. Beyond these suggested requirements, the standard requirements for cold spray apply and would need to be achieved, notably around the critical velocity of the powders (to fulfil the "build-up" phase). This section aims at addressing this specific factor based on the conclusions from this work as well as results provided by the literature.

Most models that define the critical velocity do not clearly account for the variability of the substrate that the metal is impinging, as they generally study same metal powder/substrate pairs (Ref 56, 61), so it is difficult to define a critical velocity required for metal deposition onto CFRP. Nevertheless, by taking the critical velocity of metals on metals and the maximal advisable impact energy for polymeric substrates (Ref 26), it is possible to establish a relation between the velocity of the particle and a desirable particle size to obtain deformation of the powder, and therefore deposition. Morphology can vary to affect the velocity of the powders in flight and density is immutable to the material considered, so only the diameter of the powder could be reasonably modified.

From Eq $1, \quad E_{c}=\frac{1}{2} * \rho * \frac{4}{3} \pi r_{\mathrm{p}}^{3} * v_{\text {crit }}^{2}, \quad$ or $E_{c}=\frac{1}{2} * \frac{4}{3} \pi \frac{d_{\mathrm{p}}^{3}}{8} * \rho * v_{\text {crit }}^{2}$, we can obtain Eq 6:

$d_{\mathrm{p}}=\sqrt[3]{\frac{12 * E_{c}}{\pi * \rho * v_{\text {crit }}^{2}}}$

where $d_{\mathrm{p}}$ is the diameter of the particle and $v_{\text {crit }}$ is its critical velocity. The critical velocity varies as a function of the particle size, but given recent empirical results (Ref 62), it seems that the critical velocity of several materials ( $\mathrm{Al}, \mathrm{Ni}, \mathrm{Cu}, \mathrm{Zn}$ ) only varies by $10-30 \mathrm{~m} / \mathrm{s}$ for particle sizes ranging from 14 to $30 \mu \mathrm{m}$. Therefore, a first order assumption would be to assume that the critical velocity varies slightly for a varying particle size, and so the critical velocity is considered as a constant. By taking $E_{c}=$ $2 \times 10^{-6} \mathrm{~J}$ as a kinetic energy limit for deposition (Ref 26), theoretical particle size limitations can be calculated, as presented in Table 6.

This table shows the difficulty to spray most powders on CFRP as most particles would need to be relatively small (below $15 \mu \mathrm{m}$, while cold spray uses powders generally between 5 and $50 \mu \mathrm{m})$. This could provide some level of difficulty to address as smaller powders are generally not desired: they are presumed to be greatly affected by the bow shock that appears in the gas flow, which leads them to being slower than would be expected (Ref 63, 64). The results from Table 6 also shows that $S n$ is relatively easier to spray with a more flexible particle size. Also, the varying critical velocity between references has a limited effect on the indicated diameters, as can be seen with copper $(50 \mathrm{~m} / \mathrm{s}$ difference between both references, and only lum limit differences for the maximum powder diameter for deposition), which supports the assumption that the variation of critical velocity with particle size that should be accounted for can be deemed minimal in front of the overall limitation on particle sizes.

Results in the literature support smaller particle sizes for deposition, as shown in the works of Gillet et al. (Ref 31), where differently sized $\mathrm{Cu}$ powders were cold sprayed onto CFRP substrates. The fine powder of their work led to the deposition of $\mathrm{Cu}$ onto the CFRP, with indicated impact energies of $3.9 .10^{-7} \mathrm{~J}$, whereas the medium and large powders had impact energies of 10 or 100 times greater, which led to cratering and erosive behavior (Ref 31). The works of Affi et al. (Ref 17) explored the cold spraying of small Al particles $(15 \mu \mathrm{m})$ on a CFRP substrate, but this only resulted in erosion of the substrate: no indication of particle velocity was recorded here, so it is possible that energy (i.e velocity) of the particles was too high for deposition, or the proportion of powders above the maximum powder size (Table 6) was too large. In a second experiment of the same study, they also sprayed smaller $\mathrm{Al}$ particles $(3 \mu \mathrm{m})$ to account for the energetic limitation advanced by Lupoi and O'Neill (Ref 26), and were able to obtain thin coatings (Ref 17).

It should be noted that this discussion only considers deposition and does not address the condition of the coatings (the deposited coatings were not optimal as porosity persisted (Ref 31 ) or peeling occurred (Ref 17)), nor does it address other improvement techniques such as interlayer deposition (Ref 17) or spraying in multiple steps (Ref 31). Typically, in the second part of their work, Gillet et al. (Ref 31) sprayed fine powders after having sprayed the medium or large powders and obtained growing coatings, which may be due to roughening provided by the medium or large powders.

The initial observation that no peeling occurred while cutting the samples from this study may indicate a difference in mechanical properties of these coatings as compared to those of the coatings with $\mathrm{SC} \mathrm{Al} / \mathrm{Al}$ alloy in (Ref 46); therefore a follow-up study on coating properties will be considered to fully assess the effect the SC properties on the coating properties such as adhesion strength, and not only on the deposition as was the case here. 
Table 6 Theoretical maximal powder diameters for deposition on CFRP with a maximal kinetic energy of $E_{c}=2 \times 10^{-6} \mathrm{~J}$, based on critical velocities from the literature (Ref 56, 62)

\begin{tabular}{|c|c|c|c|c|}
\hline $\begin{array}{c}\text { Hardness close to CFRP } \\
\text { hardness }\end{array}$ & Powder & $\begin{array}{l}\text { Density } \\
\mathrm{g} / \mathrm{cm}^{3}\end{array}$ & $\begin{array}{l}\text { Critical velocity (for particles around } 25 \mu \mathrm{m} \text { ) } \\
\mathrm{m} / \mathrm{s}\end{array}$ & $\begin{array}{l}\text { Maximum powder diameter for deposition } \\
\mu \mathrm{m}\end{array}$ \\
\hline \multirow[t]{8}{*}{ Yes } & $\mathrm{Sn}$ & 7.29 & $180(\operatorname{Ref} 56)$ & 32 \\
\hline & $\mathrm{Pb}$ & 11.35 & $130(\operatorname{Ref} 56)$ & 34 \\
\hline & $\mathrm{Cu}$ & 8.96 & $553(\operatorname{Ref} 62)$ & 14 \\
\hline & & & $500(\operatorname{Ref} 56)$ & 15 \\
\hline & $\mathrm{Al}$ & 2.70 & $800(\operatorname{Ref} 62)$ & 16 \\
\hline & & & $660(\operatorname{Ref} 56)$ & 19 \\
\hline & $\mathrm{Zn}$ & 7.10 & $520(\operatorname{Ref} 62)$ & 16 \\
\hline & & & $380(\operatorname{Ref} 56)$ & 20 \\
\hline \multirow[t]{3}{*}{ No } & $\mathrm{Fe}$ & 7.87 & $700(\operatorname{Ref} 56)$ & 14 \\
\hline & SS316L & 8.00 & $750(\operatorname{Ref} 56)$ & 13 \\
\hline & $\mathrm{Ti}$ & 4.50 & $800($ Ref 56) & 12 \\
\hline
\end{tabular}

Finally, the results in this work are discussed in the light of the previously hypothesized "crack-filling" mechanism (Ref 18, 46): while this study does not provide additional proof to the occurrence of the mechanism, the obtained results further support considerations that were advanced in (Ref 46), therefore reinforcing the legitimacy of the "crack-filling" mechanism. The follow-up study on coating properties could help advance additional proof of the occurrence of the mechanism. Furthermore, while the "crack-filling" mechanism was initially developed within the framework of $\mathrm{Sn}$ deposition on epoxy-CFRP (i.e. a polymeric substrate that exhibits a brittle fracture behavior), it seems from (Ref 46) that the mechanism could also apply to PEEK-CFRP. Nevertheless, other studies have looked into cold-spraying on PEEK (thermoplastic) substrates and advanced embedding as a deposition mechanism, facilitated by thermal deformation of the substrate (Ref 24, 34-36). While this mechanism could also play a role when depositing on the PEEK-CFRP, the low pressure and relatively lower temperature conditions applied here with $\mathrm{Sn}$ feedstock powder may not be sufficient to notably induce this mechanism, and previous results (Fig. 8 of (Ref 46)) would seem to support this.

\section{Conclusions}

Tin was mixed in 90:10 weight ratio with various secondary components that covered a wider spread of hardness, density, morphology and median sizes than previous studies concerning cold spray of mixed powders on to CFRPs. These mixtures were cold sprayed with a CenterLine low-pressure cold spray system, onto thermosetting
epoxy-CFRP substrates with varying surface finishes, a thermoplastic PEEK-CFRP and mild steel substrates. The secondary components of this study offered varying degrees of improvement as compared to what had previously been observed, and the effect of secondary component properties on the overall deposition efficiency, and effective deposition efficiencies of pure tin and of the secondary component, were discussed:

- The results confirm the ideal hardness range that was identified in the previous study with secondary component $\mathrm{Al}$ and $\mathrm{Al}$ alloys, and that would be within the hardness range of the substrates.

- Morphology of the secondary component was confirmed to have a significant role in the retention of the secondary component in the coating, and while spherical morphologies generally lead to increased overall deposition, more irregular morphologies would often lead to a decrease.

- The SC density, morphology and median particle size do not seem to reveal a specific trend on their own, but the SC impact energy seems to be a key factor in the improvement of Sn deposition on CFRP. Most notably, while SC with low hardness and low impact energy seem to provide the greatest improvement for pure Sn deposition, SC with higher impact energy lead to erosion, and SC with higher hardness lead to decreased pure Sn DE.

Based on this study and on previous work, it was possible to provide insight into the key conditions for deposition of Sn on CFRP with mixed powders. Furthermore, by extending the observations on $\mathrm{SC}$ to single component powders, limitations on powder hardness and impact 
energy were discussed for deposition of metals onto CFRP: these conditions seem to rest on smaller particle sizes for particles with higher critical velocities. The properties of such directly deposited coatings may not be ideal, and future work will focus on studying adhesion of the mixedpowder coatings, versus the deposition of these powders.

Acknowledgments The authors wish to acknowledge the financial support of the Natural Sciences and Engineering Research Council of Canada (NSERC) through the Green-SEAM strategic network and the McGill Engineering Doctoral Award (MEDA). The industrial partners, Bombardier Aerospace and Tencate (through Pratt and Whitney Canada) are gratefully acknowledged. Mr. Kévin Bricault from National Research Council Canada, Boucherville, is acknowledged for his contribution to the cold spray experiments.

\section{References}

1. R. Gonzalez, H. Ashrafizadeh, A. Lopera, P. Mertiny and A. McDonald, A Review of Thermal Spray Metallization of Polymer-Based Structures, J. Therm. Spray Technol., 2016, 25(5), p 897-919.

2. F. Faupel, V. Zaporojtchenko, T. Strunskus, J. Erichsen, K. Dolgner, A. Thran and M. Kiene, Fundamental aspects of polymer metallization, Metallization of Polymers, Vol 2, E. Sacher Ed., Springer, Montréal, 2002, p 73-96

3. A. Rahimi, M. Hojjati, A. Dolatabadi and C. Moreau, Thermal Spray Coating on Polymeric Composite for De-Icing and AntiIcing Applications, J. Manuf. Sci. Eng., 2021, 143(10), p 101008.

4. S. Black, Lightning Strike Protection Strategies for Composite Aircraft, High-Perform. Compos. Compos. World, 2013, 21(3), p 52-61.

5. J. Siegel and V. Kotál, Preparation of Thin Metal Layers on Polymers, Acta Polytech., 2007, 47(1), p 9-11.

6. T. Duguet, F. Senocq, L. Laffont and C. Vahlas, Metallization of Polymer Composites by Metalorganic Chemical Vapor Deposition of Cu: Surface Functionalization Driven Films Characteristics, Surf. Coat. Technol., 2013, 230, p 254-259.

7. S. Kuroda, J. Kawakita, M. Watanabe and H. Katanoda, Warm Spraying-A Novel Coating Process Based on High-Velocity Impact of Solid Particles, Sci. Technol. Adv. Mat., 2008, 9(3), p 033002 .

8. G. Archambault, B. Jodoin, S. Gaydos and M. Yandouzi, Metallization of Carbon Fiber Reinforced Polymer Composite by Cold Spray and Lay-Up Molding Processes, Surf. Coat. Technol., 2016, 300, p 78-86.

9. R. Wang, D. Song, W. Liu and X. He, Effect of Arc Spraying Power on the Microstructure and Mechanical Properties of Zn-Al Coating Deposited onto Carbon Fiber Reinforced Epoxy Composites, Appl. Surf. Sci., 2010, 257(1), p 203-209.

10. C. Feng, M. Gibbons and S. Chandra, Fabrication of Composite Heat Sinks Consisting of a Thin Metallic Skin and a Polymer Core Using Wire-Arc Spraying, J. Therm. Spray Technol., 2019, 28(5), p 974-985.

11. S. Devaraj, B. Anand, M. Gibbons, A. McDonald and S. Chandra, Thermal Spray Deposition of Aluminum and Zinc Coatings on Thermoplastics, Surf. Coat. Technol., 2020, 399, p 126114.

12. K. Bobzin, W. Wietheger and M.A. Knoch, Development of Thermal Spray Processes for Depositing Coatings on Thermoplastics, J. Therm. Spray Technol., 2021, 30(1-2), p 157-167.

13. R. Gonzalez, A. McDonald and P. Mertiny, Effect of FlameSprayed Al-12Si Coatings on the Failure Behaviour of
Pressurized Fibre-Reinforced Composite Tubes, Polym. Test., 2013, 32(8), p 1522-1528.

14. A. Wypych, P. Siwak, D. Andrzejewski and J. Jakubowicz, Titanium Plasma-Sprayed Coatings on Polymers for Hard Tissue Applications, Materials, 2018, 11(12), p 2536.

15. S. Guanhong, H. Xiaodong, J. Jiuxing and S. Yue, Parametric Study of $\mathrm{Al}$ and $\mathrm{Al}_{2} \mathrm{O}_{3}$ Ceramic Coatings Deposited by Air Plasma Spray onto Polymer Substrate, Appl. Surf. Sci., 2011, 257(17), p 7864-7870.

16. W. Huang, X. Fan, Y. Zhao, X. Zhou, X. Meng, Y. Wang, B. Zou, X. Cao and Z. Wang, Fabrication of Thermal Barrier Coatings onto Polyimide Matrix Composites via Air Plasma Spray Process, Surf. Coat. Technol., 2012, 207, p 421-429.

17. J. Affi, H. Okazaki, M. Yamada and M. Fukumoto, Fabrication of Aluminum Coating onto CFRP Substrate by Cold Spray, Mater. Trans., 2011, 52(9), p 1759-1763.

18. H. Che, P. Vo and S. Yue, Metallization of Carbon Fibre Reinforced Polymers by Cold Spray, Surf. Coat. Technol., 2017, 313, p 236-247.

19. A. Ganesan, M. Yamada and M. Fukumoto, Cold Spray Coating Deposition Mechanism on the Thermoplastic and Thermosetting Polymer Substrates, J. Therm. Spray Technol., 2013, 22(8), p 1275-1282.

20. A. Ganesan, M. Yamada and M. Fukumoto, The Effect of CFRP Surface Treatment on the Splat Morphology and Coating Adhesion Strength, J. Therm. Spray Technol., 2013, 23(1-2), p 236-244.

21. D. Zhang, P.H. Shipway and D.G. McCartney, Cold Gas Dynamic Spraying of Aluminum: The Role of Substrate Characteristics in Deposit Formation, J. Therm. Spray Technol., 2005, 14(1), p 109-116.

22. R. Della Gatta, A.S. Perna, A. Viscusi, G. Pasquino and A. Astarita, Cold Spray Deposition of Metallic Coatings on Polymers: A Review. J. Mater. Sci., 2022, 57, p 27-57.

23. R. Melentiev, N. Yu and G. Lubineaua, Polymer Metallization via Cold Spray Additive Manufacturing: A Review of Process Control, Coating Qualities, and Prospective Applications, Addit. Manuf., 2021, 48, p 102459.

24. H. Che, X. Chu, P. Vo and S. Yue, Metallization of Various Polymers by Cold Spray, J. Therm. Spray Technol., 2017, 27(1-2), p 169-178.

25. J. Sun, S. Zhou, K. Yamanaka, Y. Ichikawa, H. Saito, K. Ogawa and A. Chiba, Thermal Effects in Sn Coating on a Carbon Fiber Reinforced Plastic by Cold Spraying, J. Therm. Spray Technol., 2021, 30(5), p 1254-1261.

26. R. Lupoi and W. O'Neill, Deposition of Metallic Coatings on Polymer Surfaces using Cold Spray, Surf. Coat. Technol., 2010, 205(7), p 2167-2173.

27. R. Della Gatta, A. Viscusi, A. Serena Perna, A. Caraviello and A. Astarita, Feasibility of Steel Powder Deposition on Composites through Cold Spray, Mater. Manuf. Process., 2021, 36(3), p 281-291.

28. A.S. Perna, A. Astarita, P. Carlone, X. Guthmann and A. Viscusi, Characterization of Cold-Spray Coatings on Fiber-Reinforced Polymers through Nanoindentation Tests, Metals, 2021, 11(2), p 1-16.

29. R. Della Gatta, A. Viscusi, A. Serena Perna, A. Caraviello and A. Astarita, Cold Spray Process for the Production of AlSi10Mg Coatings on Glass Fibers Reinforced Polymers, Mater. Manuf. Process., 2021, 36(1), p 106-121.

30. A. Viscusi, V. Antonucci, L. Carrino, R. Della Gatta, V. Lopresto, I. Papa, A.S. Perna, M.R. Ricciardi and A. Astarita, Manufacturing of an Innovative Composite Structure: Design, Manufacturing and Impact Behaviour, Compos. Struct., 2020, 250, p 112637. 
31. V. Gillet, E. Aubignat, S. Costil, B. Courant, C. Langlade, P. Casari, W. Knapp and M.P. Planche, Development of Low Pressure Cold Sprayed Copper Coatings on Carbon Fiber Reinforced Polymer (CFRP), Surf. Coat. Technol., 2019, 364, p 306-316.

32. L.L. Koithara, R.N. Raoelison, S. Costil and X. Xie, High Deposition Efficiency and Delamination Issues during HighPressure Cold Spraying Metallization of PEEK using Spherical Copper Powders, Int. J. Adv. Manuf. Technol., 2020, 107(11-12), p 4427-4436.

33. P. Lomonaco, S. Weiller, I. Feki, A. Debray, F. Delloro, M. Jeandin, B. Favini and C. Rossignol, Cold Spray Technology to Promote Conductivity of Short Carbon Fiber Reinforced Polyether-Ether-Ketone (PEEK), Key Eng. Mater., 2019, 813, p 459-464.

34. R.N. Raoelison, L.L. Koithara and S. Costil, Cold Spray Coating of PEEK Surface by Copper Deposition: Interfacial Adhesion at High Deposition Efficiency and Bonding Strength, CIRP J. Manuf. Sci. Technol., 2021, 35, p 63-68.

35. H. Liu, N.U.H. Tariq, Y. Ren, J. Luo, H. Liu, L.J. Zhao, X. Cui, J. Wang and T. Xiong, Effect of Accelerating Gas Temperature on Microstructure and Properties of Cold Sprayed Al Coating on Polyether Ether Ketone (PEEK), Surf. Coat. Technol., 2022, 429, p 127972

36. C. Chen, X. Xie, Y. Xie, X. Yan, C. Huang, S. Deng, Z. Ren and H. Liao, Metallization of Polyether Ether Ketone (PEEK) by Copper Coating via Cold Spray, Surf. Coat. Technol., 2018, 342, p 209-219.

37. E. Irissou, J.-G. Legoux, B. Arsenault and C. Moreau, Investigation of $\mathrm{Al}-\mathrm{Al}_{2} \mathrm{O}_{3}$ Cold Spray Coating Formation and Properties, J. Therm. Spray Technol., 2007, 16(5-6), p 661-668.

38. H. Koivuluoto and P. Vuoristo, Effect of Powder Type and Composition on Structure and Mechanical Properties of $\mathrm{Cu}+$ $\mathrm{Al}_{2} \mathrm{O}_{3}$ Coatings Prepared by using Low-Pressure Cold Spray Process, J. Therm. Spray Technol., 2010, 19(5), p 1081-1092.

39. H.Y. Lee, Y.H. Yu, Y.C. Lee, Y.P. Hong and K.H. Ko, Cold Spray of $\mathrm{SiC}$ and $\mathrm{Al}_{2} \mathrm{O}_{3}$ With Soft Metal Incorporation: A Technical Contribution, J. Therm. Spray Technol., 2004, 13(2), p 184-189.

40. X.-T. Luo, Y.-K. Wei, Y. Wang and C.-J. Li, Microstructure and Mechanical Property of Ti and Ti6Al4V Prepared by an In-Situ Shot Peening Assisted Cold Spraying, Mater. Des., 2015, 85, p 527-533.

41. Y.-K. Wei, Y.-J. Li, Y. Zhang, X.-T. Luo and C.-J. Li, Corrosion Resistant Nickel Coating with Strong Adhesion on AZ31B Magnesium Alloy Prepared by an In-Situ Shot-Peening-Assisted Cold Spray, Corros. Sci., 2018, 138, p 105-115.

42. Y.-K. Wei, X.-T. Luo, C.-X. Li and C.-J. Li, Optimization of InSitu Shot-Peening-Assisted Cold Spraying Parameters for Full Corrosion Protection of $\mathrm{Mg}$ Alloy by Fully Dense Al-Based Alloy Coating, J. Therm. Spray Technol., 2017, 26(1-2), p 173-183.

43. R. Fernandez and B. Jodoin, Cold Spray Aluminum-Alumina Cermet Coatings: Effect of Alumina Content, J. Therm. Spray Technol., 2018, 27(4), p 603-623.

44. R. Fernandez and B. Jodoin, Cold Spray Aluminum-Alumina Cermet Coatings: Effect of Alumina Morphology, J. Therm. Spray Technol., 2019, 28(4), p 737-755.

45. H. Che, X. Chu, P. Vo and S. Yue, Cold Spray of Mixed Metal Powders on Carbon Fibre Reinforced Polymers, Surf. Coat. Technol., 2017, 329, p 232-243.

46. A.C. Liberati, H. Che, P. Vo and S. Yue, Influence of Secondary Component Hardness When Cold Spraying Mixed Metal Powders on Carbon Fiber Reinforced Polymers, J. Therm. Spray Technol., 2021, 30(5), p 1239-1253.

47. H. Che, A. Liberati, P. Vo and S. Yue, Cold Spray of Mixed Sn$\mathrm{Zn}$ and Sn-Al Powders on Carbon Fiber Reinforced Polymers, Mater. Sci. Forum, 2018, 941, p 1892-1897.
48. R. Carlson and J.E. Carlson, 1.11-The study of experimental factors, Comprehensive Chemometrics. S.D. Brown, R. Tauler, B. Walczak Ed., Elsevier, 2009, p 301-344

49. X. Chu, H. Che, P. Vo, R. Chakrabarty, B. Sun, J. Song and S. Yue, Understanding the Cold Spray Deposition Efficiencies of 316L/Fe Mixed Powders by Performing Splat Tests onto AsPolished Coatings, Surf. Coat. Technol., 2017, 324, p 353-360.

50. X. Chu, R. Chakrabarty, H. Che, L. Shang, P. Vo, J. Song and S. Yue, Investigation of the Feedstock Deposition Behavior in a Cold Sprayed 316L/Fe Composite Coating, Surf. Coat. Technol., 2018, 337, p 53-62.

51. W. Wong, P. Vo, E. Irissou, A.N. Ryabinin, J.-G. Legoux and S. Yue, Effect of Particle Morphology and Size Distribution on Cold-Sprayed Pure Titanium Coatings, J. Therm. Spray Technol., 2013, 22(7), p 1140-1153.

52. A. Liberati, H. Che, P. Vo and S. Yue, Cold spraying of mixed Sn-Al powders onto carbon fibre reinforced polymers, ITSC 2018-Proceedings of the International Thermal Spray Conference. F. Azarmi, K. Balani, T. Eden, T. Hussain, Y.-C. Lau, H. Li, K. Shinoda Ed., ASM International, Orlando, 2018, p 166-172

53. D. Poirier, J.-G. Legoux, P. Vo, B. Blais, J.D. Giallonardo and P.G. Keech, Powder Development and Qualification for HighPerformance Cold Spray Copper Coatings on Steel Substrates, $J$. Therm. Spray Technol., 2019, 28(3), p 444-459.

54. O.Ç. Özdemir, J.M. Conahan and S. Müftü, Particle Velocimetry CFD, and the Role of Particle Sphericity in Cold Spray, Coatings, 2020, 10(12), p 1254.

55. A.C. Liberati, H. Che, P. Vo and S. Yue, Observation of an Indirect Deposition Effect while Cold Spraying Sn-Al Mixed Powders onto Carbon Fiber Reinforced Polymers, J. Therm. Spray Technol., 2020, 29, p 134-146.

56. T. Schmidt, F. Gärtner, H. Assadi and H. Kreye, Development of a Generalized Parameter Window for Cold Spray Deposition, Acta Mater., 2006, 54(3), p 729-742.

57. S. Kuroda, M. Watanabe, K. Kim and H. Katanoda, Current Status and Future Prospects of Warm Spray Technology, J. Therm. Spray Technol., 2011, 20(4), p 653-676.

58. Z. Zeng, N. Sakoda, T. Tajiri and S. Kuroda, Structure and Corrosion Behavior of 316L Stainless Steel Coatings Formed by HVAF Spraying With and Without Sealing, Surf. Coat. Technol., 2008, 203(3), p 284-290.

59. N.-M. Barkoula and J. Karger-Kocsis, Review Processes and Influencing Parameters of the Solid Particle Erosion of Polymers and their Composites, J. Mater. Sci., 2002, 37(18), p 3807-3820.

60. N. Miyazaki and N. Takeda, Solid Particle Erosion of Fiber Reinforced Plastics, J. Compos. Mater., 1993, 27(1), p 21-31.

61. H. Assadi, T. Schmidt, H. Richter, J.-O. Kliemann, K. Binder, F. Gärtner, T. Klassen and H. Kreye, On Parameter Selection in Cold Spraying, J. Therm. Spray Technol., 2011, 20(6), p 1161-1176.

62. M. Hassani-Gangaraj, D. Veysset, K.A. Nelson and C.A. Schuh, In-Situ Observations of Single Micro-Particle Impact Bonding, Scripta Mater., 2018, 145, p 9-13.

63. D. Helfritch and V. Champagne, A Model Study of Powder Particle Size Effects in Cold Spray Deposition, Army Research Lab, Aberdeen Proving Ground, 2008.

64. J. Pattison, S. Celotto, A. Khan and W. O'Neill, Standoff Distance and Bow Shock Phenomena in the Cold Spray Process, Surf. Coat. Technol., 2008, 202(8), p 1443-1454.

Publisher's Note Springer Nature remains neutral with regard to jurisdictional claims in published maps and institutional affiliations. 